Supporting information for:

\title{
Phase Behavior and Interfacial Properties of Salt-Tolerant Polymers: Insights from Molecular Dynamics Simulations
}

\author{
Safwat Abdel-Azeim* \\ Center for Integrative Petroleum Research (CIPR), College of Petroleum Engineering and Geosciences, \\ King Fahd University of Petroleum and Minerals (KFUPM), Dhahran 31261, Saudi Arabia. \\ * Corresponding author: Safwat Abdel-Azeim: abdelazeim@kfupm.edu.sa
}

Table S1: SARA compositional analysis and TAN of the crude oil. ${ }^{1}$

\begin{tabular}{l|c}
\multicolumn{2}{c}{ SARA fractional analysis (wt\%) } \\
\hline Saturates & 32.8 \\
Aromatics & 50.0 \\
Asphaltene & 2.8 \\
Resin & 11.0 \\
\hline \multicolumn{2}{c}{ Total acid number (TAN) } \\
\multicolumn{2}{c}{$6.5 \mathrm{mg} \mathrm{KOH} / \mathrm{g}$ oil }
\end{tabular}




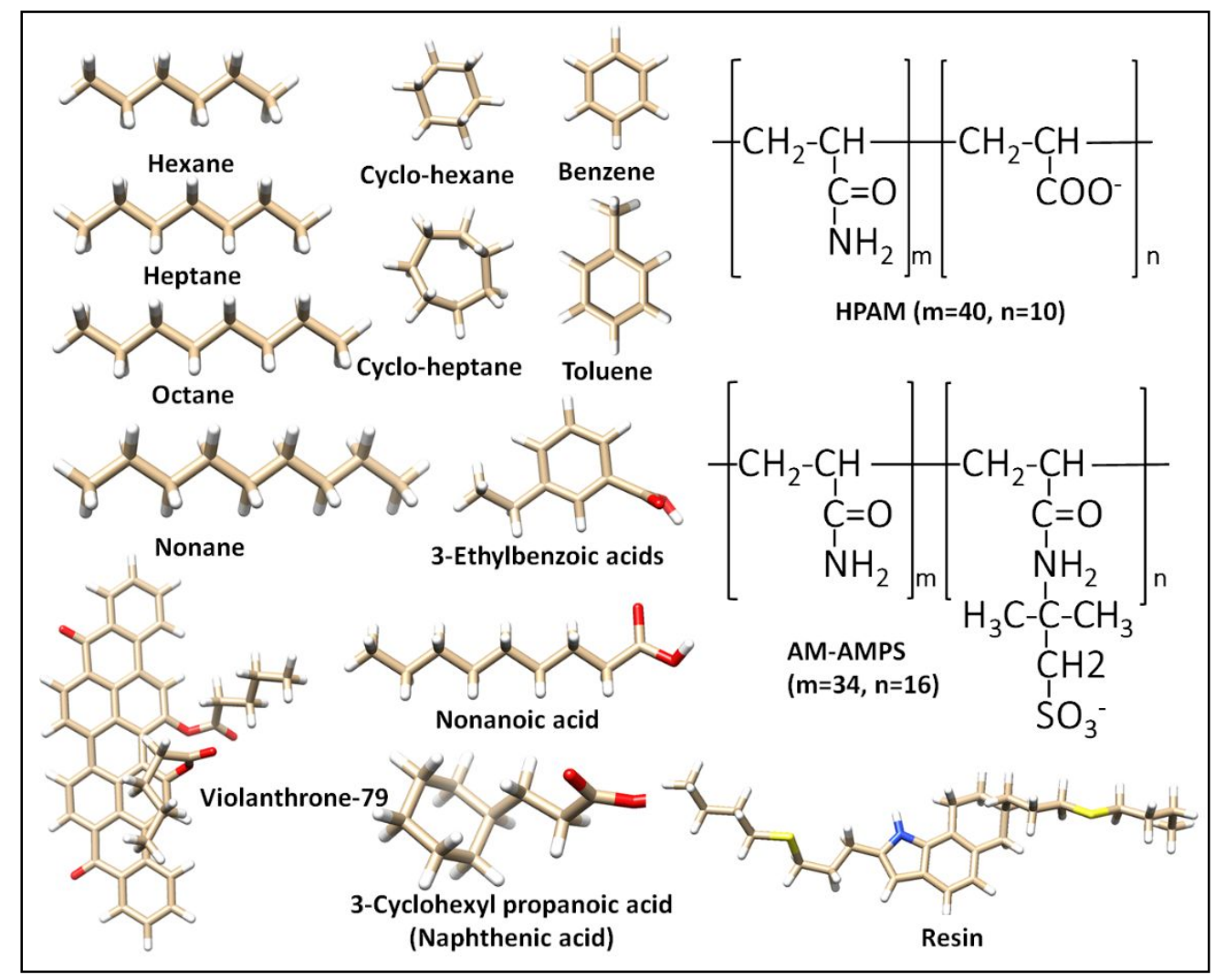

Figure S1: Molecular structures of the crude-oil components (saturates, aromatics, asphaltene, and resin), HPAM, and AM-AMPS polymers used in our MD simulations. 


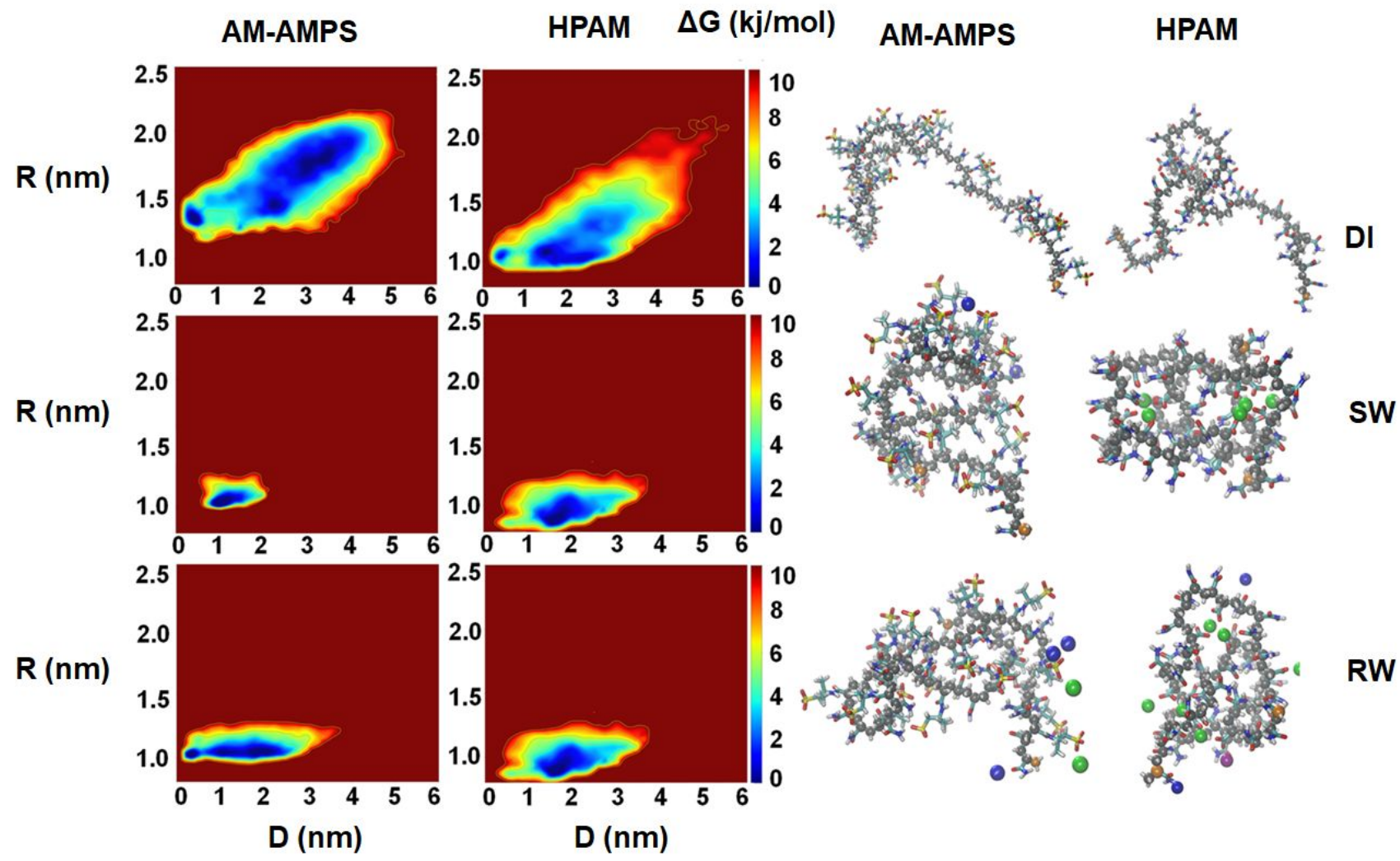

Figure S2: Free energy landescape (in $\mathrm{kj} / \mathrm{mol}$ ) contours explored in the radius of gyration $(\mathrm{R})$ and end-to-end distance (D) extracted from $3 \mu \mathrm{s}$ MD trajectories, and conducted at different salinity conditions; DI (fresh water), SW (sea water), and RW (reservoir water). Molecular structures at $3 \mu \mathrm{s}$ are also shown, polymer are shwon in licorices, backbone (gray), and ions are shown in spheres. Color code; O:red, S:yellow, C:cyan, H:white, N:blue, $\mathrm{Na+}$ : blue spheres, $\mathrm{Ca}^{2+}$ : green, and $\mathrm{Mg}^{2+}:$ purple. 
$-\mathrm{S} 2-$

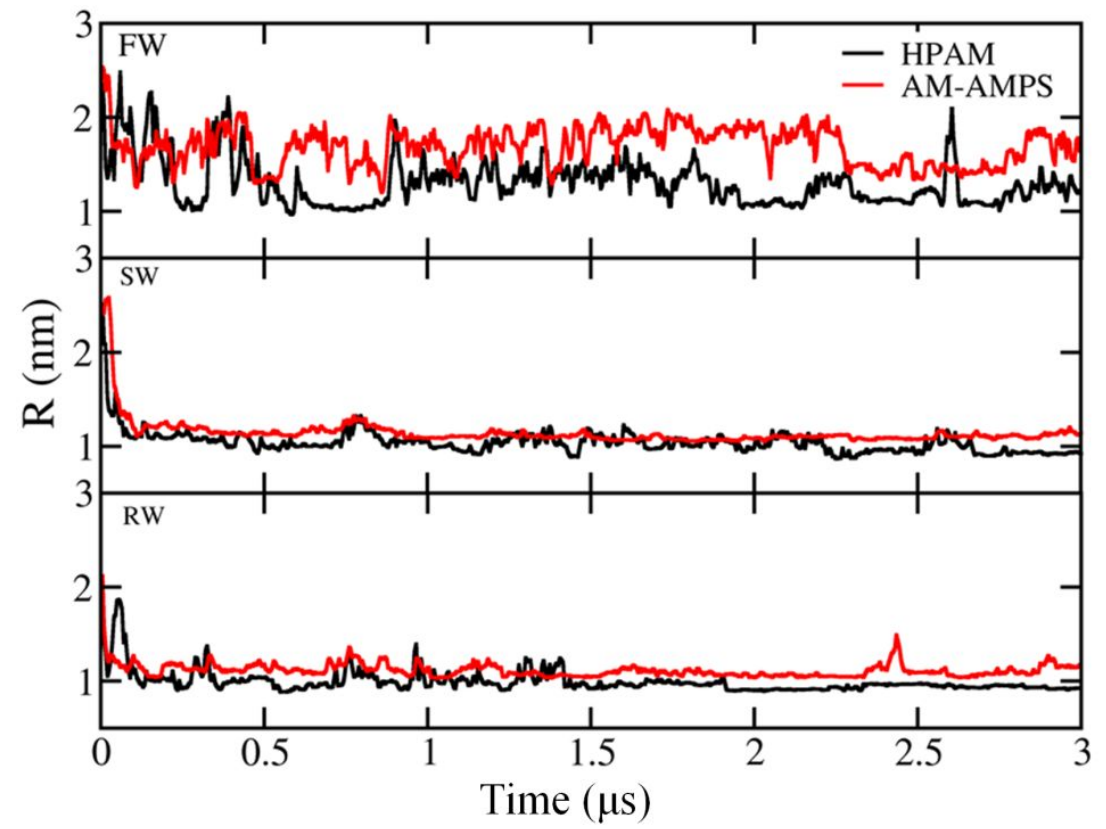

Figure S3: Radius of gyration of HPAM and AM-AMPS polymers extracted from $3 \mu \mathrm{s}$ MD trajectories. 


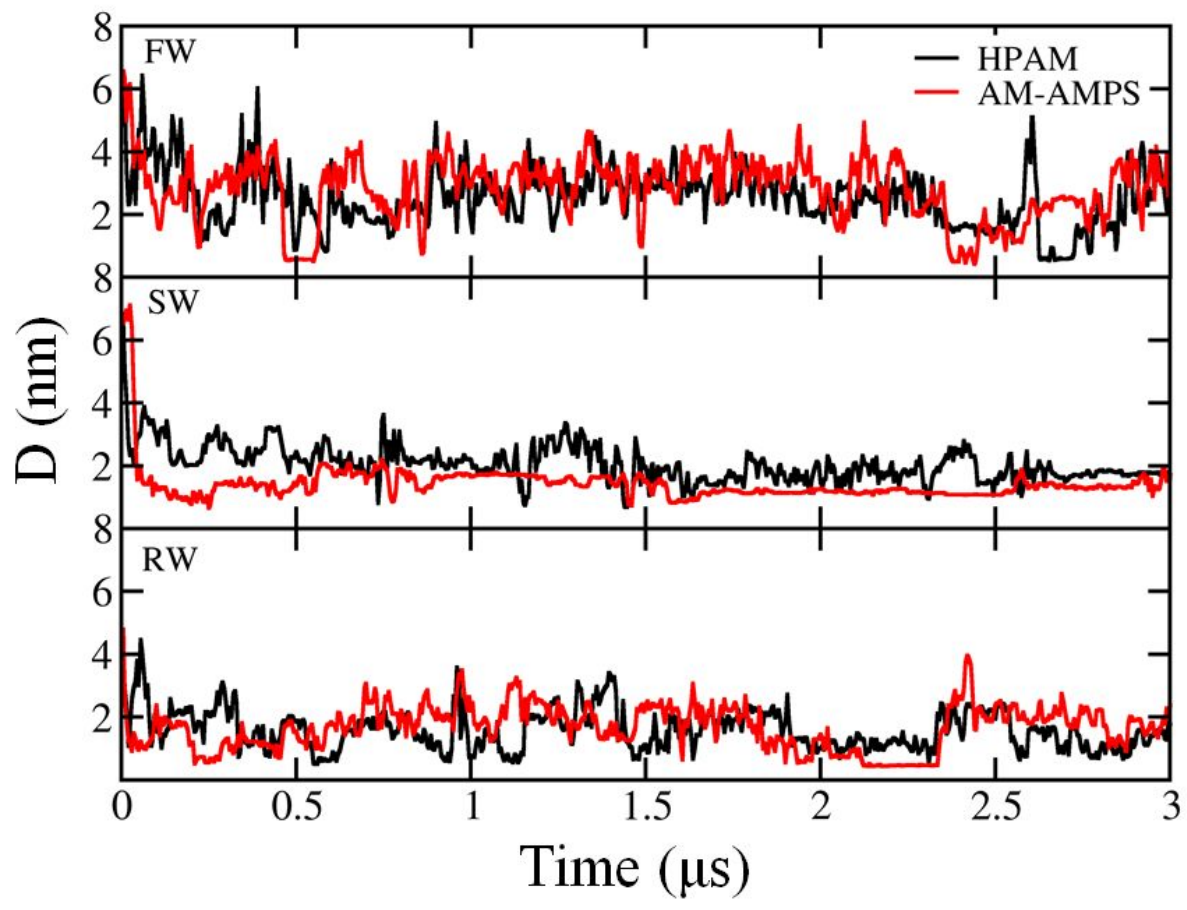

Figure S4: Radius of gyration of HPAM and AM-AMPS polymers extracted from $3 \mu \mathrm{s}$ MD trajectories.

$-\mathrm{S} 3-$

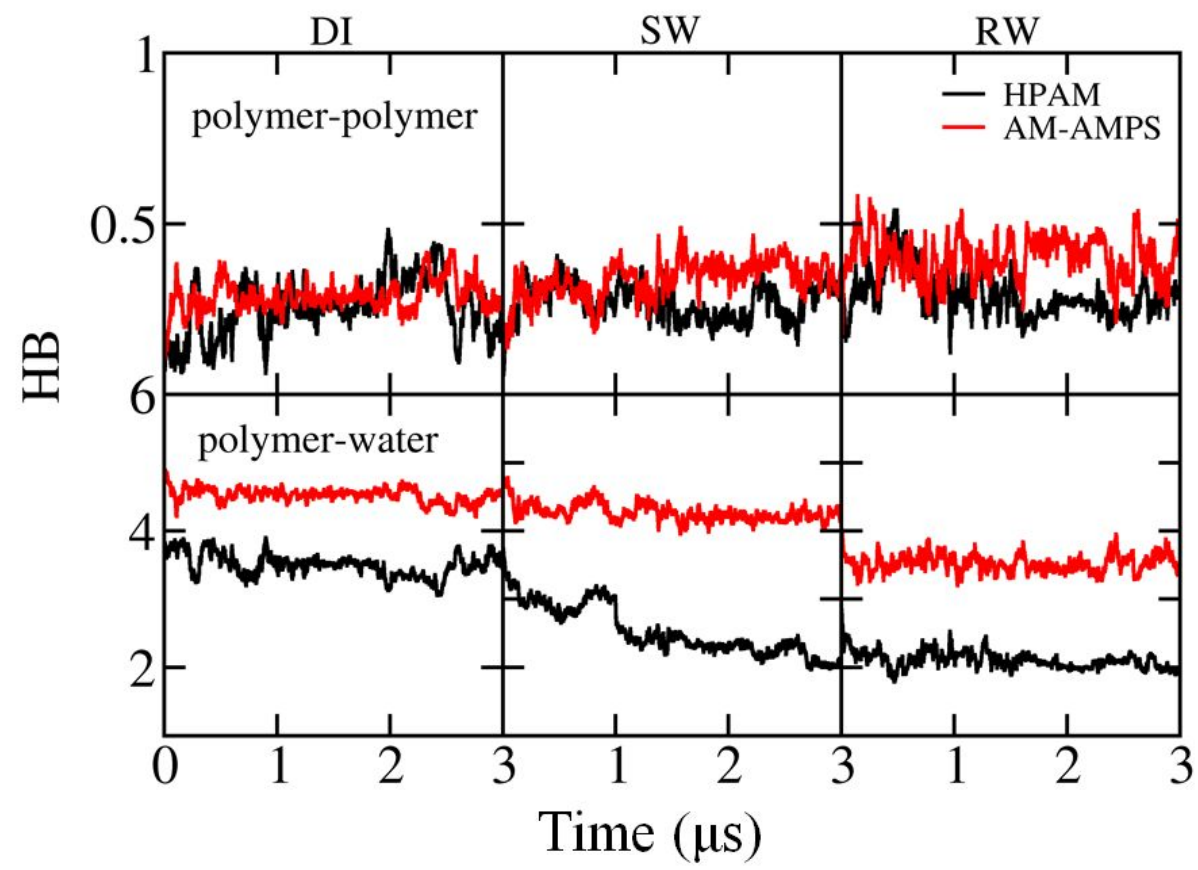


Figure S5: Hydrogen bond (HB) established between polymer-polymer (upper panel) and polymer-water (lower panel) calculated for $3 \mu \mathrm{s}$ and normalized by the degree of polymerization (i.e. 50 units) for the dilute polymer solutions of HPAM and AM-AMPS.

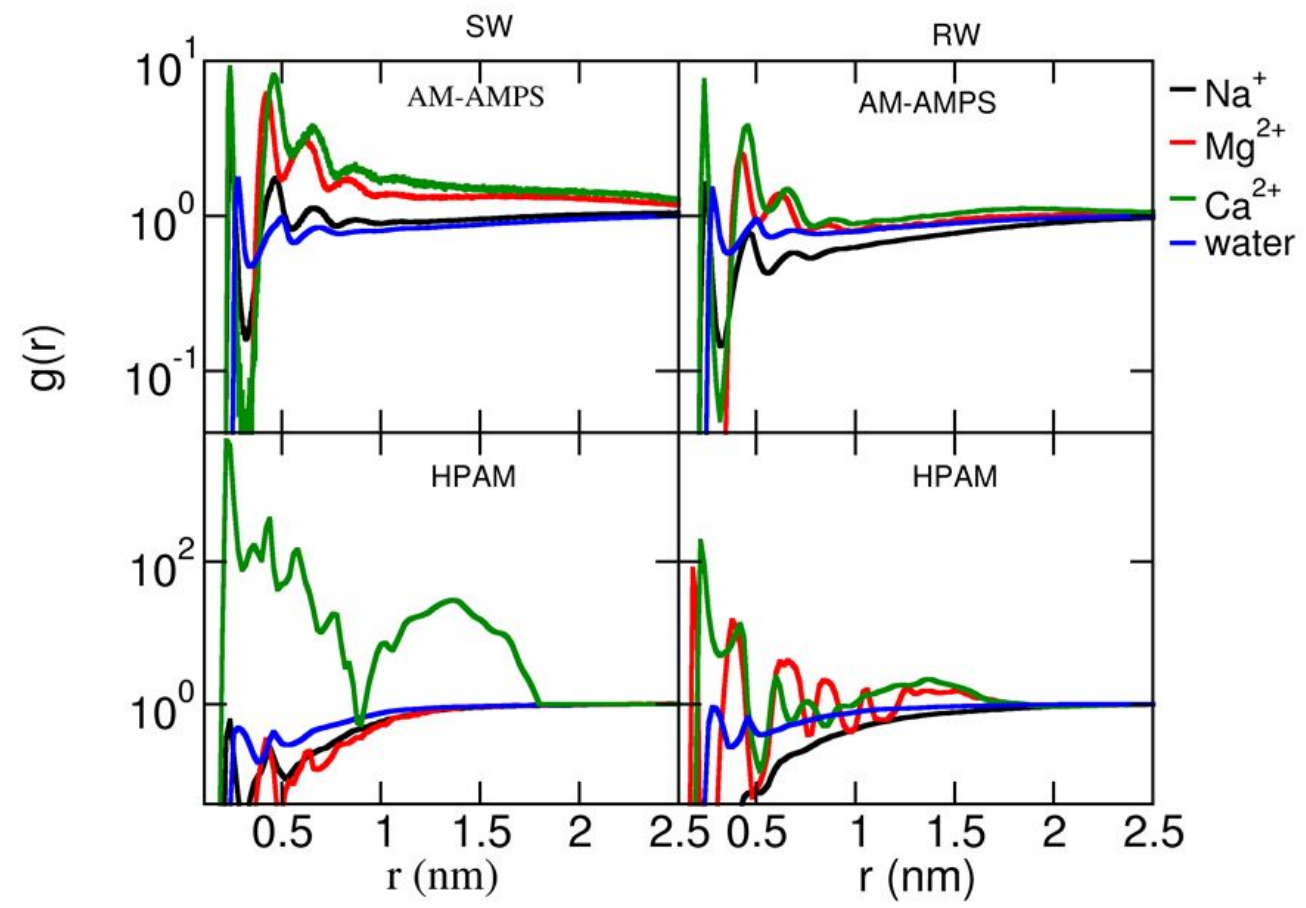

Figure S6: Radial distribution function $\mathrm{g}(\mathrm{r})$ between AMPS and AA groups with cations in SW and RW conditions (Zoom-out of Figure 3 in the main text). 


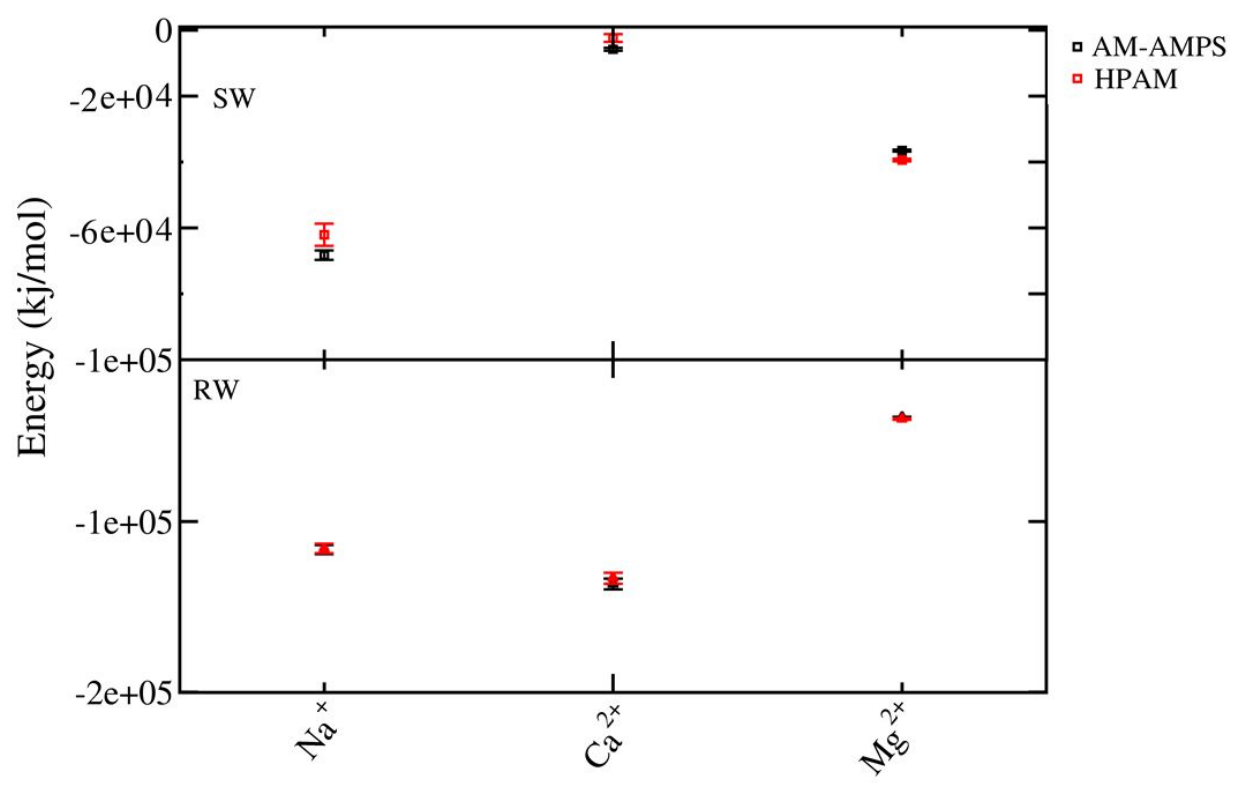

Figure S7: Total interaction energies (electrostatic and Van Der Waals (VDW)) between ions (Na, $\mathrm{Mg}, \mathrm{Ca}$ ) with water molecules in HPAM, and AM-AMPS polymer solutions.

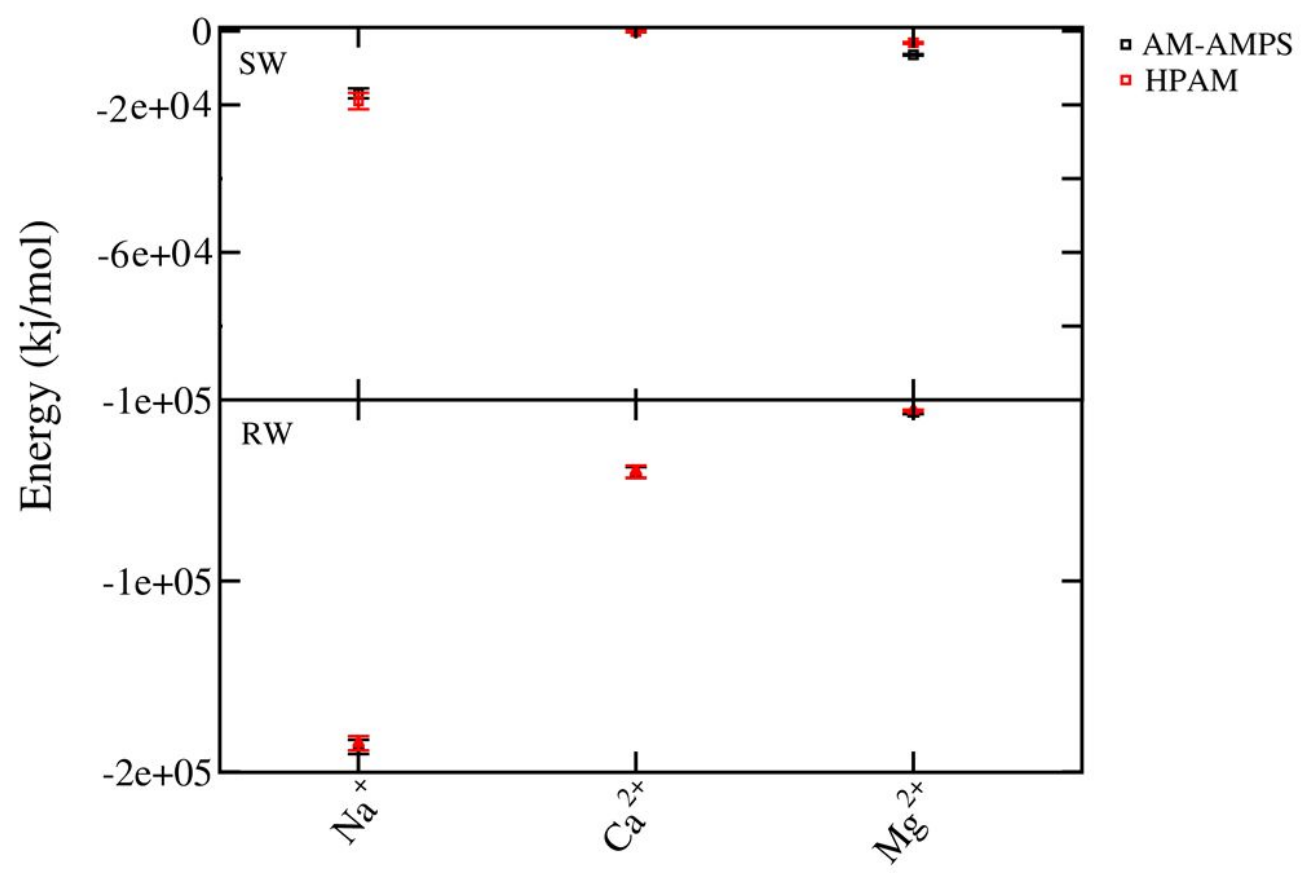

Figure S8: Total interaction energies (electrostatic and Van Der Waals (VDW)) between ions ( $\mathrm{Na}, \mathrm{Mg}, \mathrm{Ca}$ ) with $\mathrm{Cl}^{-}$anions in HPAM, and AM-AMPS polymer solutions. 
-S5-

Table S2: Interaction energies $(\mathrm{kj} / \mathrm{mol})$, and standard deviations over $3 \mu$ s between cations in $\mathrm{SW}$ and RW with Cl- ions for AM-AMPS and HPAM polymer solutions.

\begin{tabular}{|c|c|c|c|c|}
\hline \multicolumn{5}{|c|}{ AM-AMPS } \\
\hline \multicolumn{3}{|c|}{ SW } & \multicolumn{2}{|l|}{ RW } \\
\hline Cation & IE & Stdev. & IE & Stdev. \\
\hline $\mathrm{Na}+$ & -16897 & 1352 & -186772 & 3750 \\
\hline $\mathrm{Ca}^{2+}$ & -190 & 50 & -43149 & 2940 \\
\hline $\mathrm{Mg}^{2+}$ & -6490 & 195 & -12215 & 420 \\
\hline \multicolumn{5}{|c|}{ HPAM } \\
\hline $\mathrm{Na}^{+}$ & -19012 & 573.6 & -184913 & 3737 \\
\hline $\mathrm{Ca}^{2+}$ & -84 & 40 & -42706 & 3170 \\
\hline $\mathrm{Mg}^{2+}$ & -3225 & 231 & -10732 & 440 \\
\hline
\end{tabular}


-S6-

a)

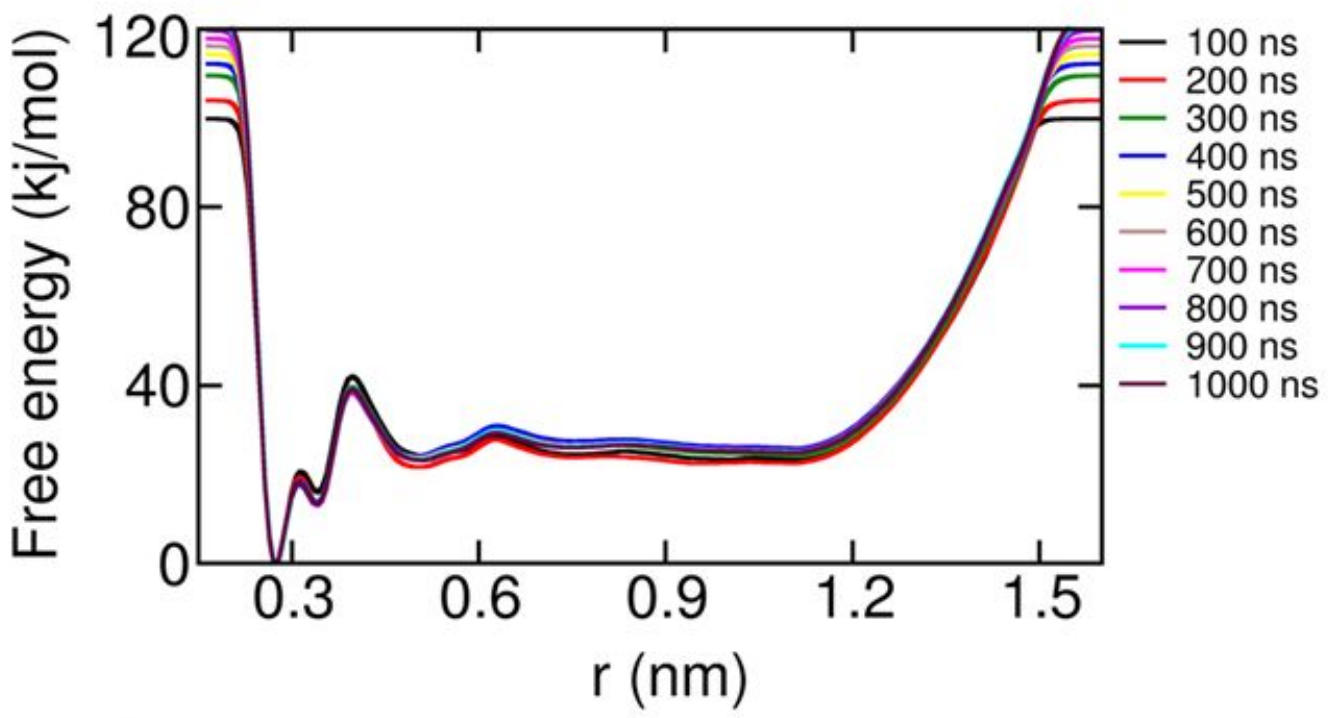

b)

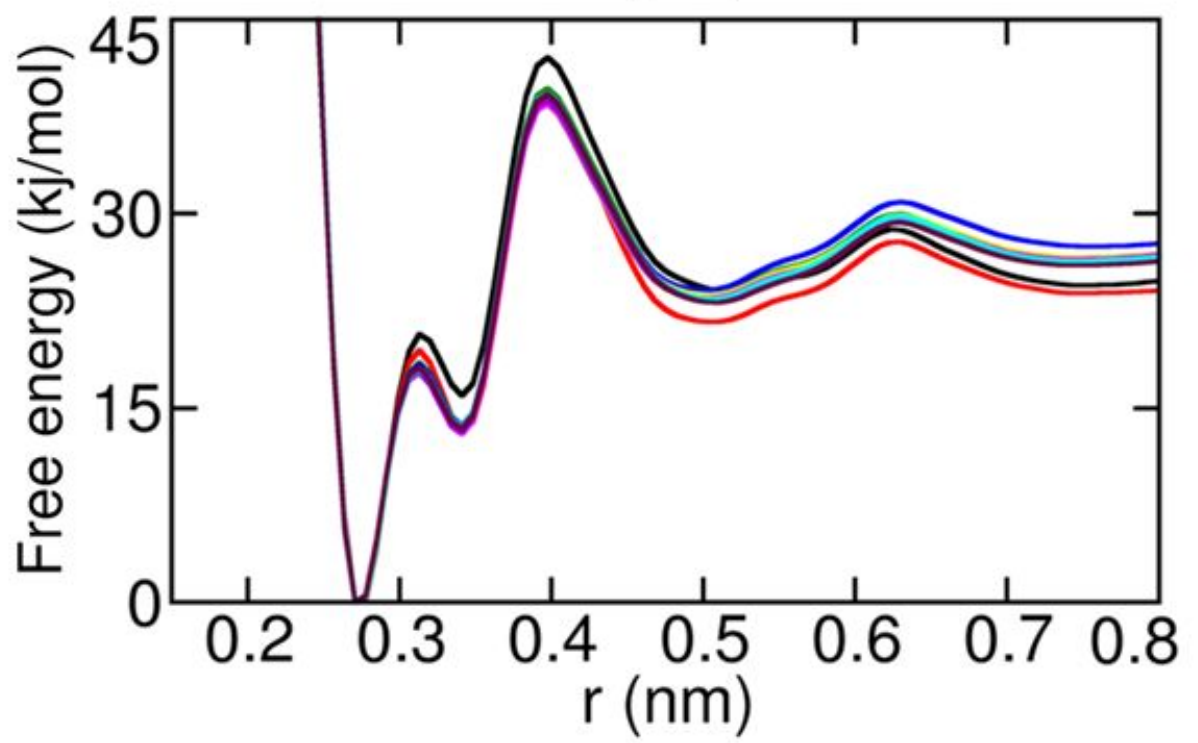

Figure S9: WTmetaD simulation of HPAM-Ca ${ }^{2+}$ binding free energy as a function of the simulation time with an interval of 100ns (a). b) is zoom-in of the plot dipected in a). 
-S7-

a)

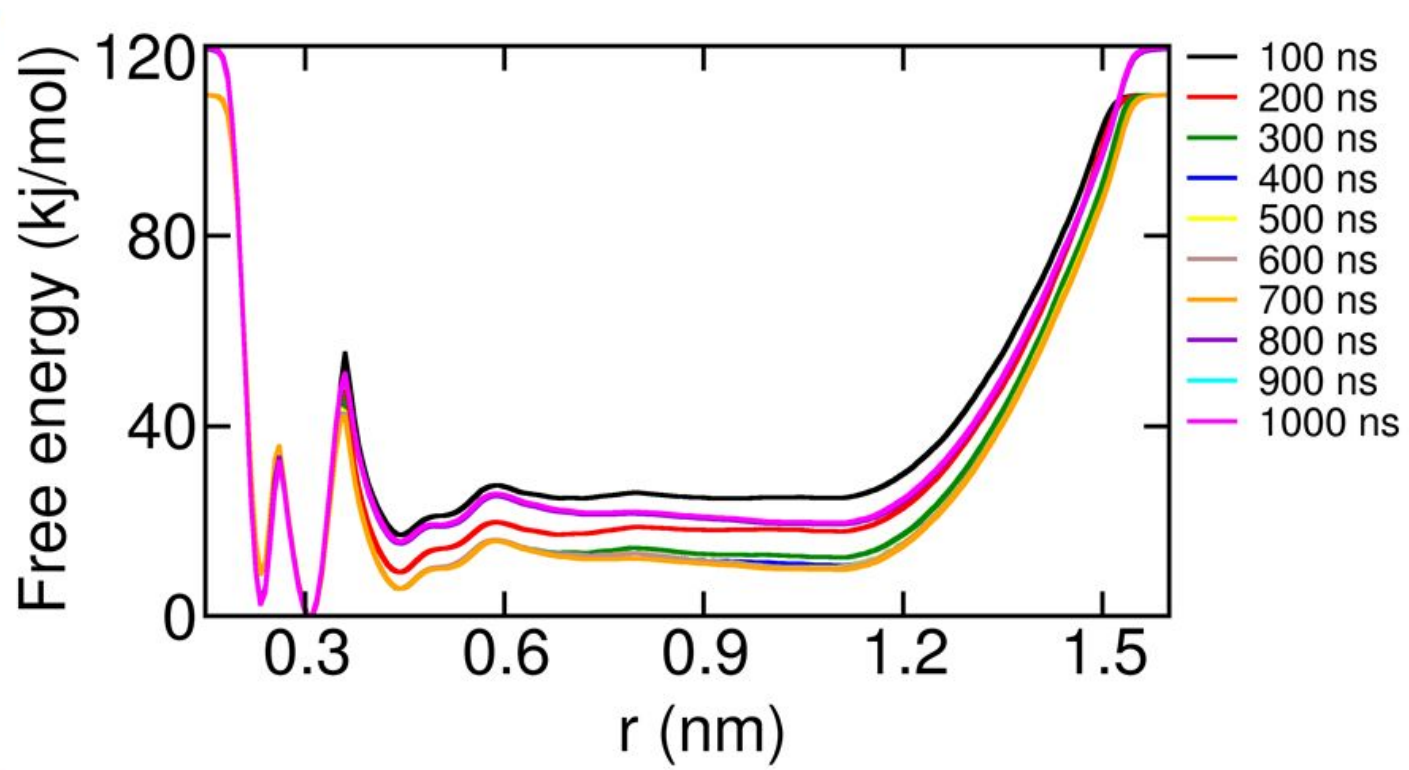

b)

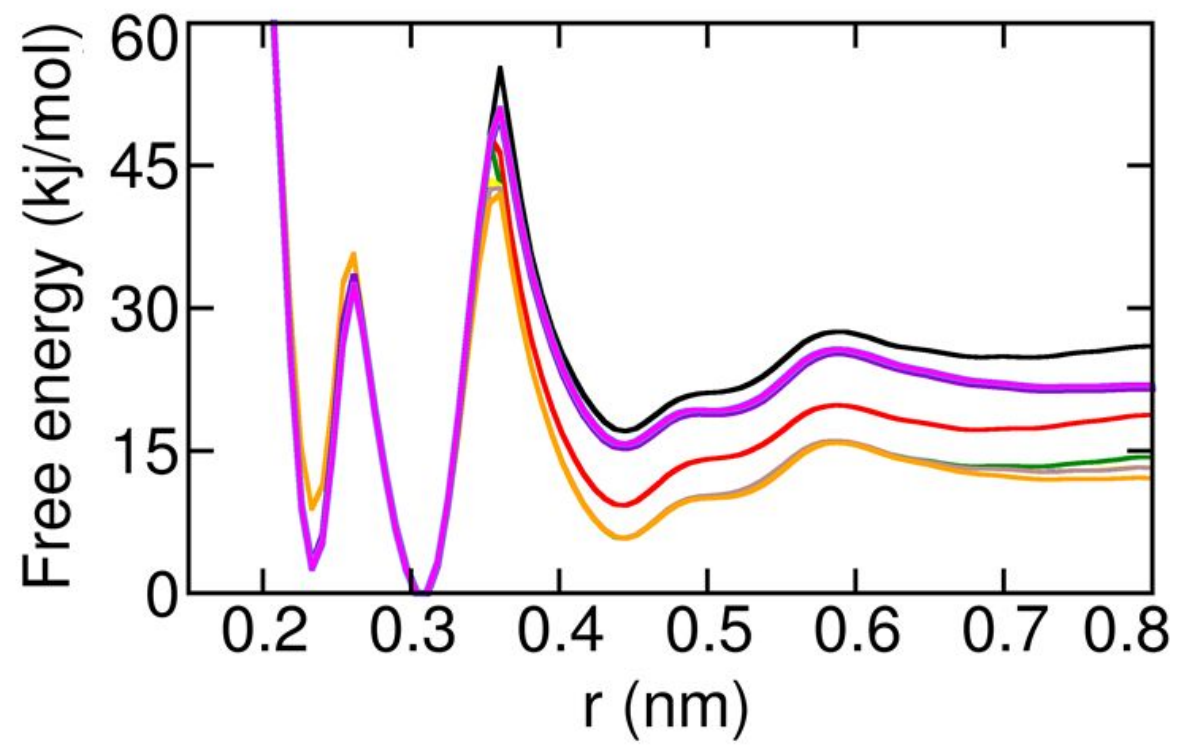


Figure S10: WTmetaD of HPAM-Mg ${ }^{2+}$ binding free energy as a function of the simulation time with an interval of 100ns (a). b) is zoom-in of the plot dipected in a).

$-\mathrm{S} 8-$
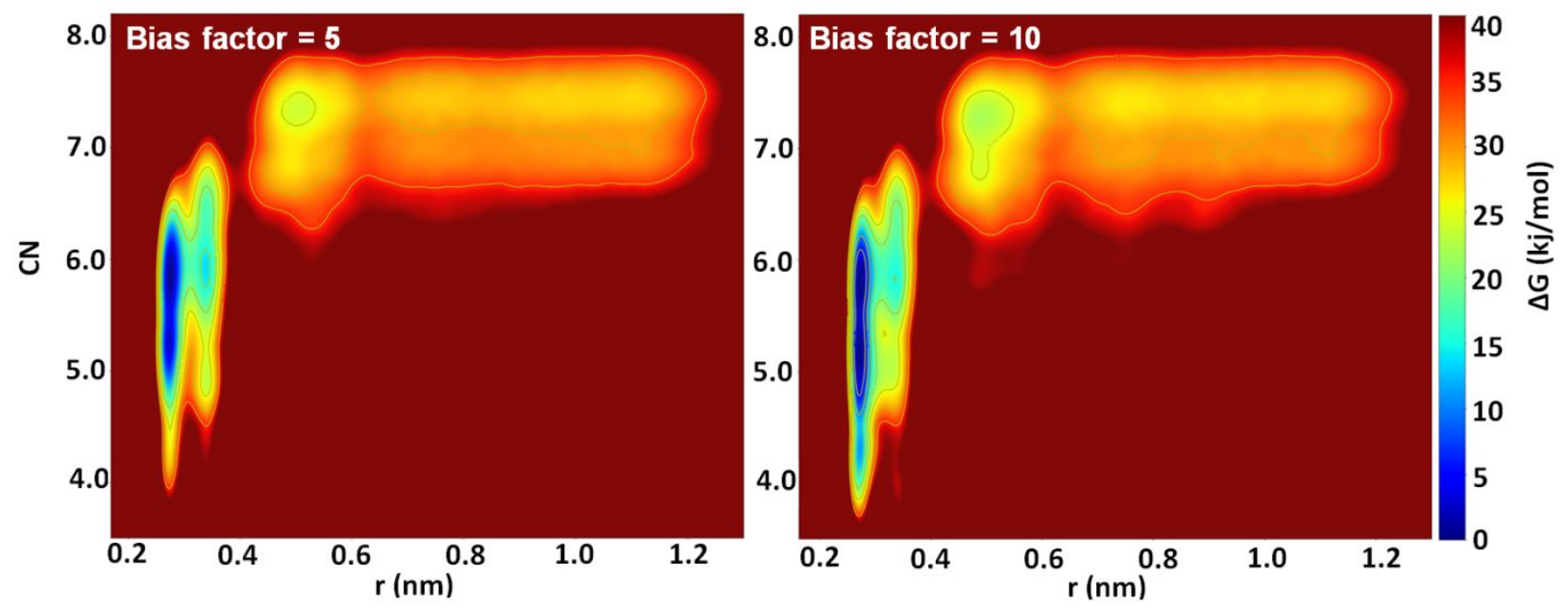

Figure S11: WTmetaD of HPAM-Ca ${ }^{2+}$ binding free energy using different bias factors estimated from 200ns trajectory to examine the effect of application of different bias factors on the free energy contour map. 

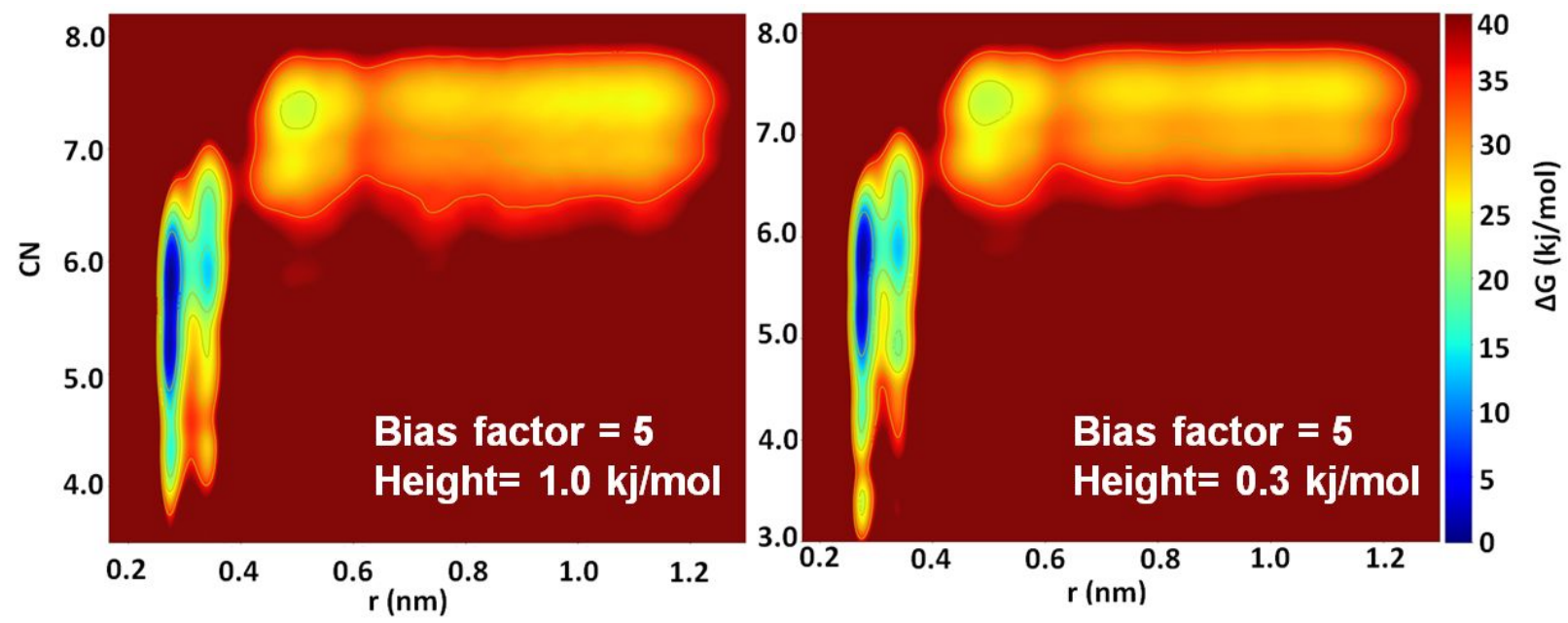

Figure S12: Free energy 2D contour map of HPAM-Ca ${ }^{2+}$ bining using different gaussian heights $1.0 \mathrm{kj} / \mathrm{mol}$ (450ns), and $0.3 \mathrm{kj} / \mathrm{mol}$ (650ns) every 200ps. 


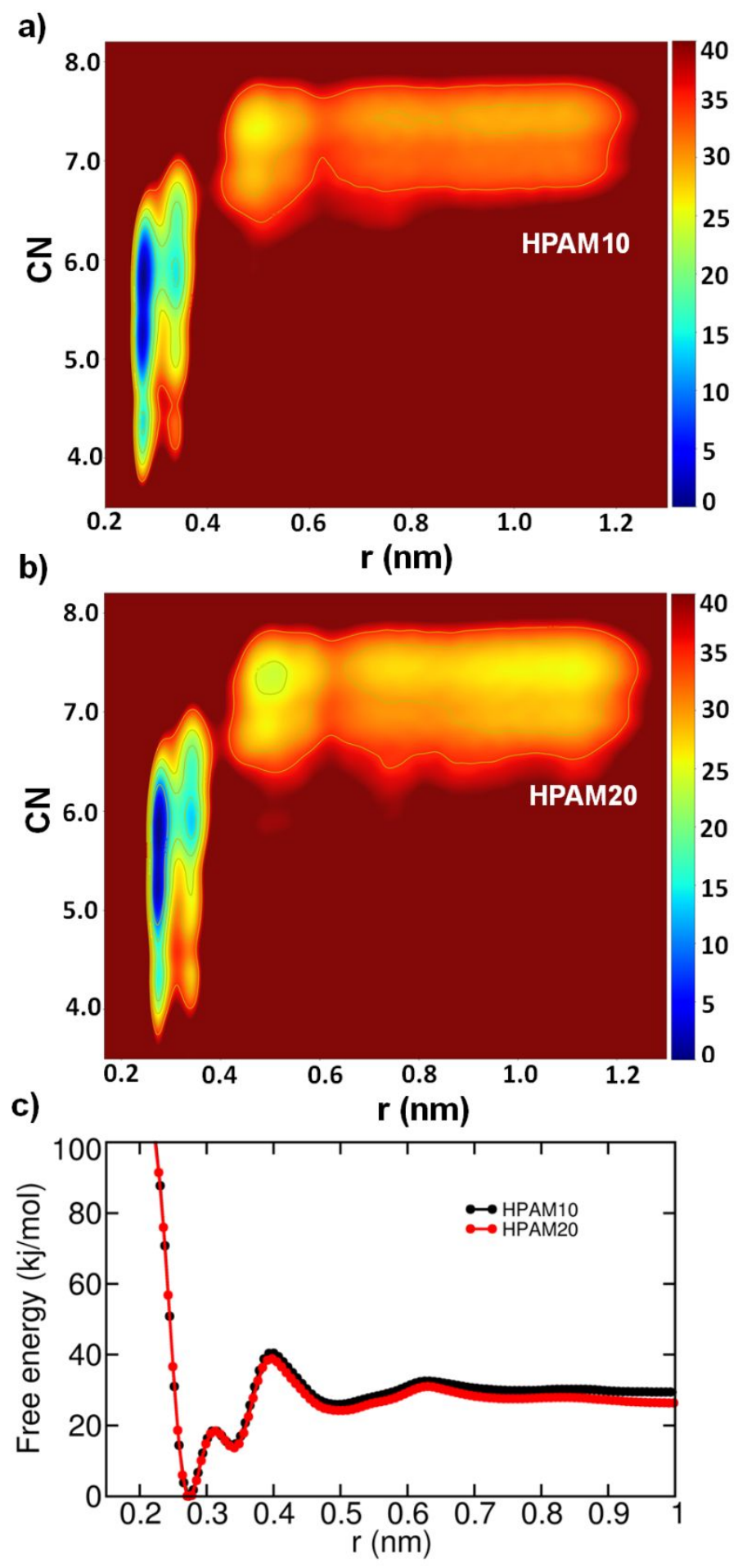

Figure S13: Free energy contour map of $\mathrm{Ca}^{2+}$-HPAM binding using different HPAM oligomer lengths with gaussian heights of $1.0 \mathrm{kj} / \mathrm{mol}$ and bias factor of 5.0 simulated for $200 \mathrm{~ns}$. 


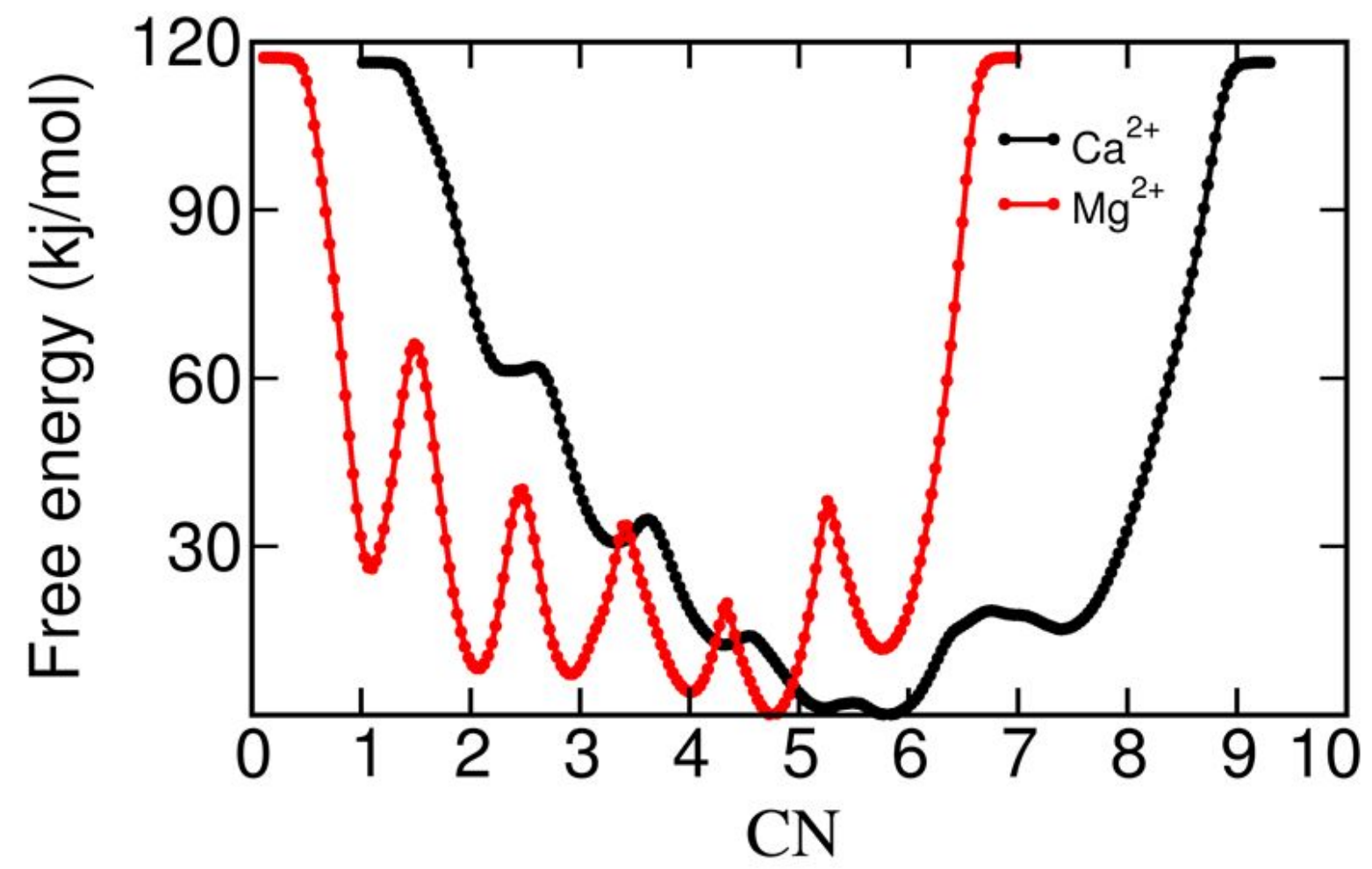

Figure S14: PMF of HPAM-Ca ${ }^{2+}$ and HPAM- $\mathrm{Mg}^{2+}$ binding free enrgies as a function of the cationwater coordination number $(\mathrm{CN})$. 
-S11- 
a)

Water $\mathrm{CN}=4$

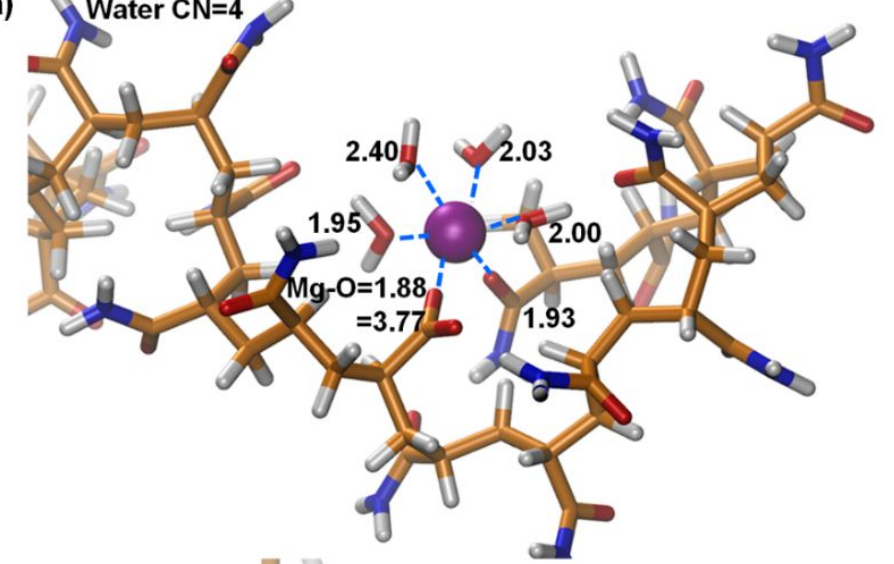

b)

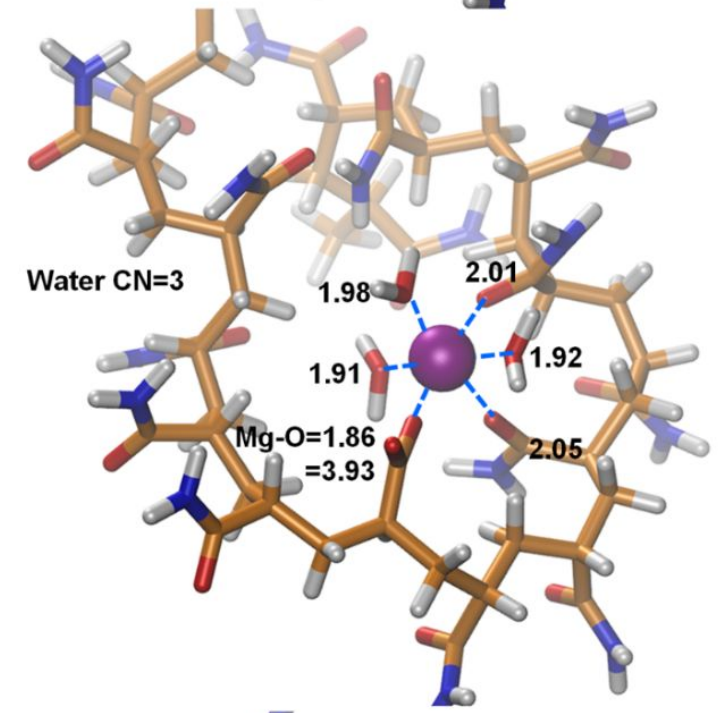

c)

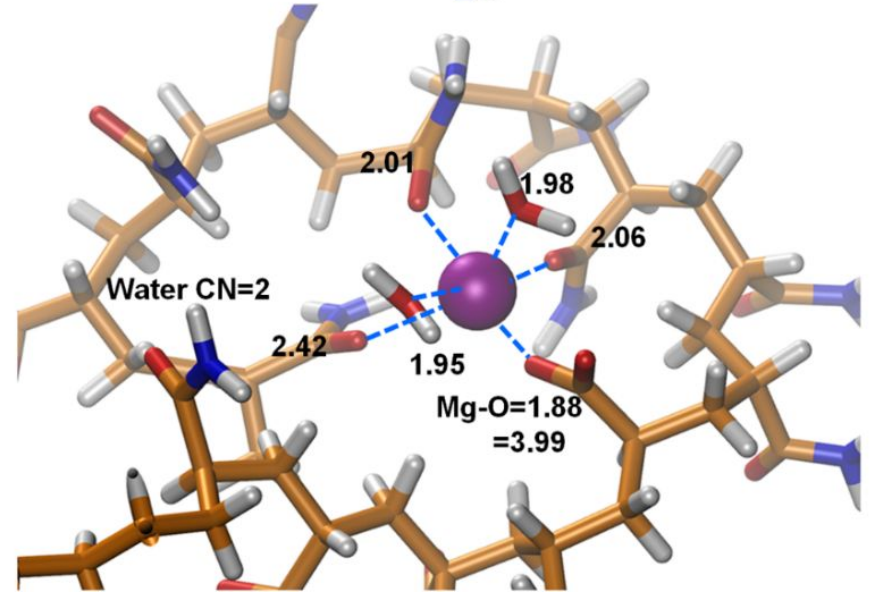

Figure S15: Key structures of $\mathrm{Mg}^{2+}-\mathrm{HPAM}$ complexes with different chelation modes and different water coordination numbers located at $\mathbf{r}=0.31 \mathrm{~nm}$. Structure VII (a), VIII (b), and IX (c). 

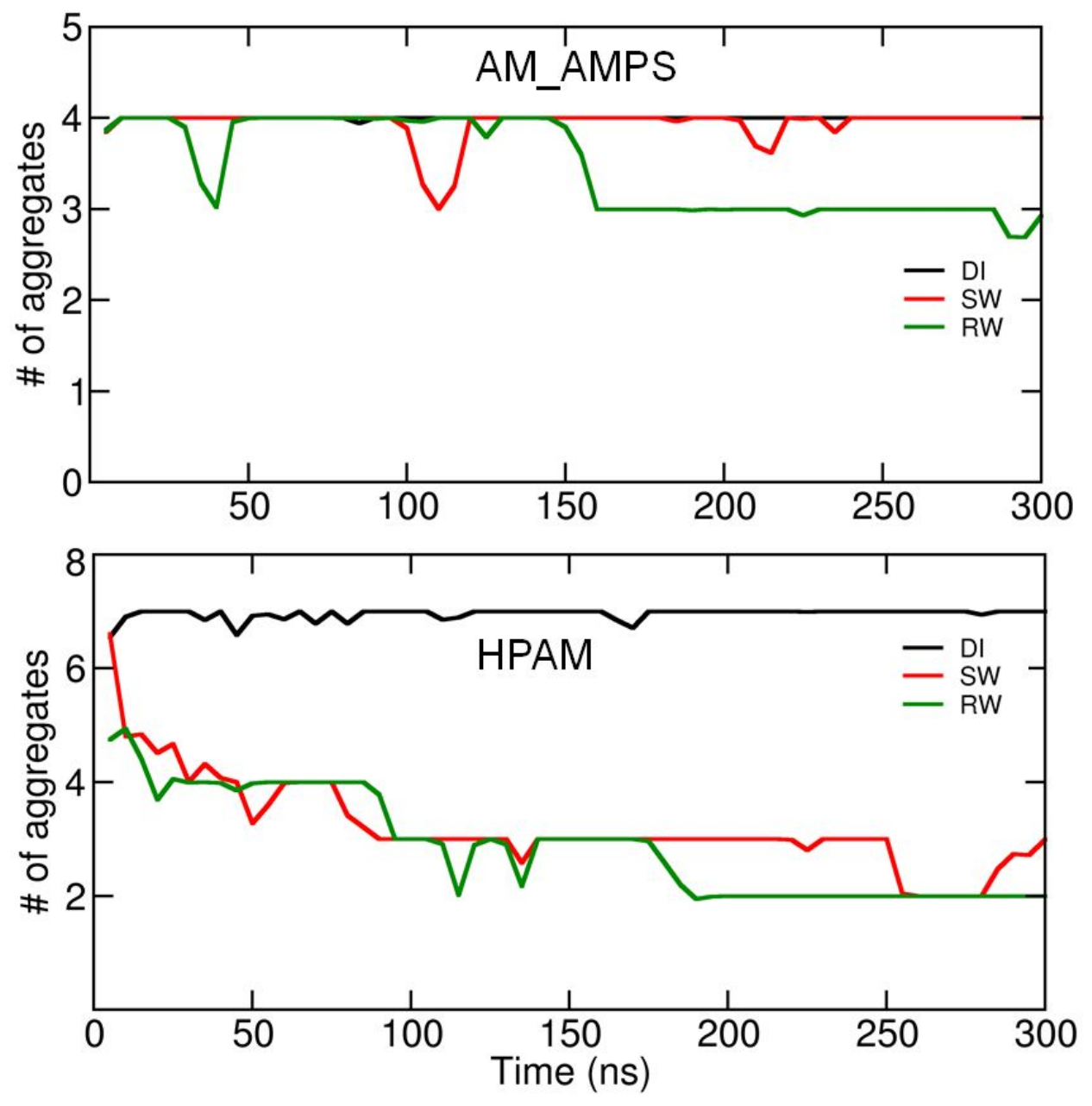

Figure S16:. The number of polymer aggregates formed during the simulation of $300 \mathrm{~ns}$ at $1.0 \mathrm{wt} \%$ polymer concentration (data shown for the first simulation run). 


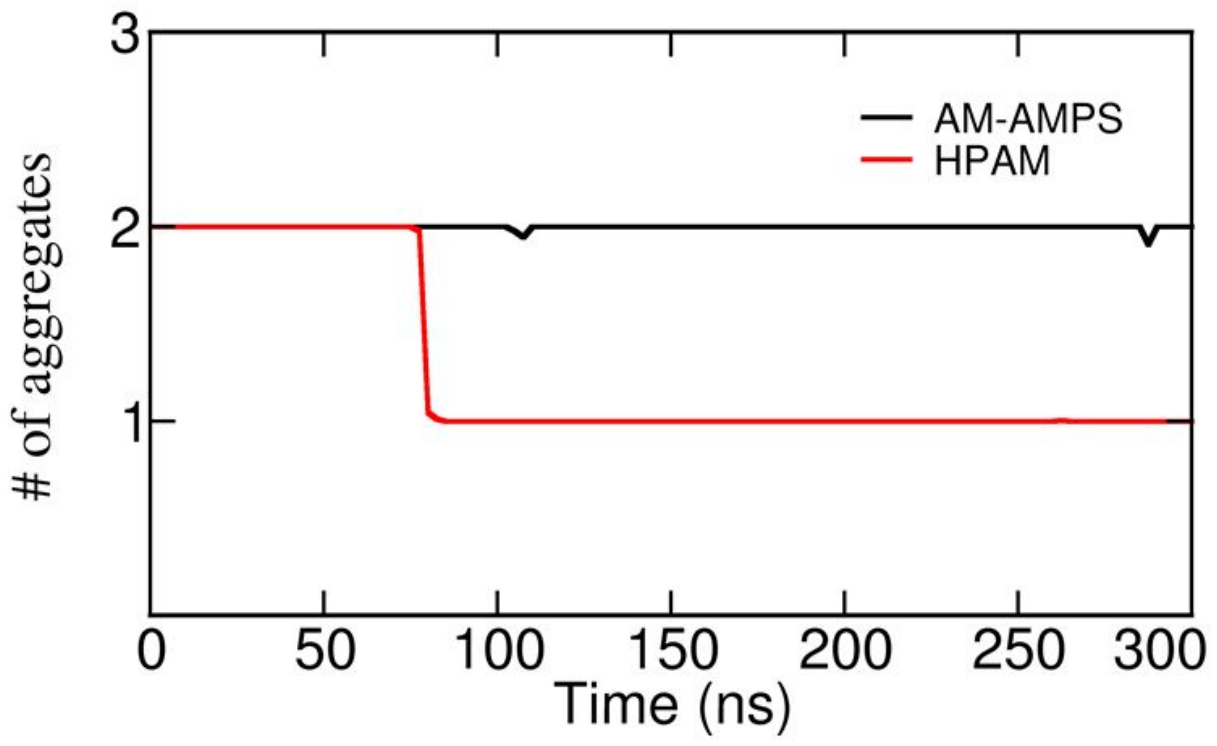

Figure S17: Number of polymer aggregates formed during the simulation of $300 \mathrm{~ns}$ at $0.5 \mathrm{wt} \%$ polymer concentration.

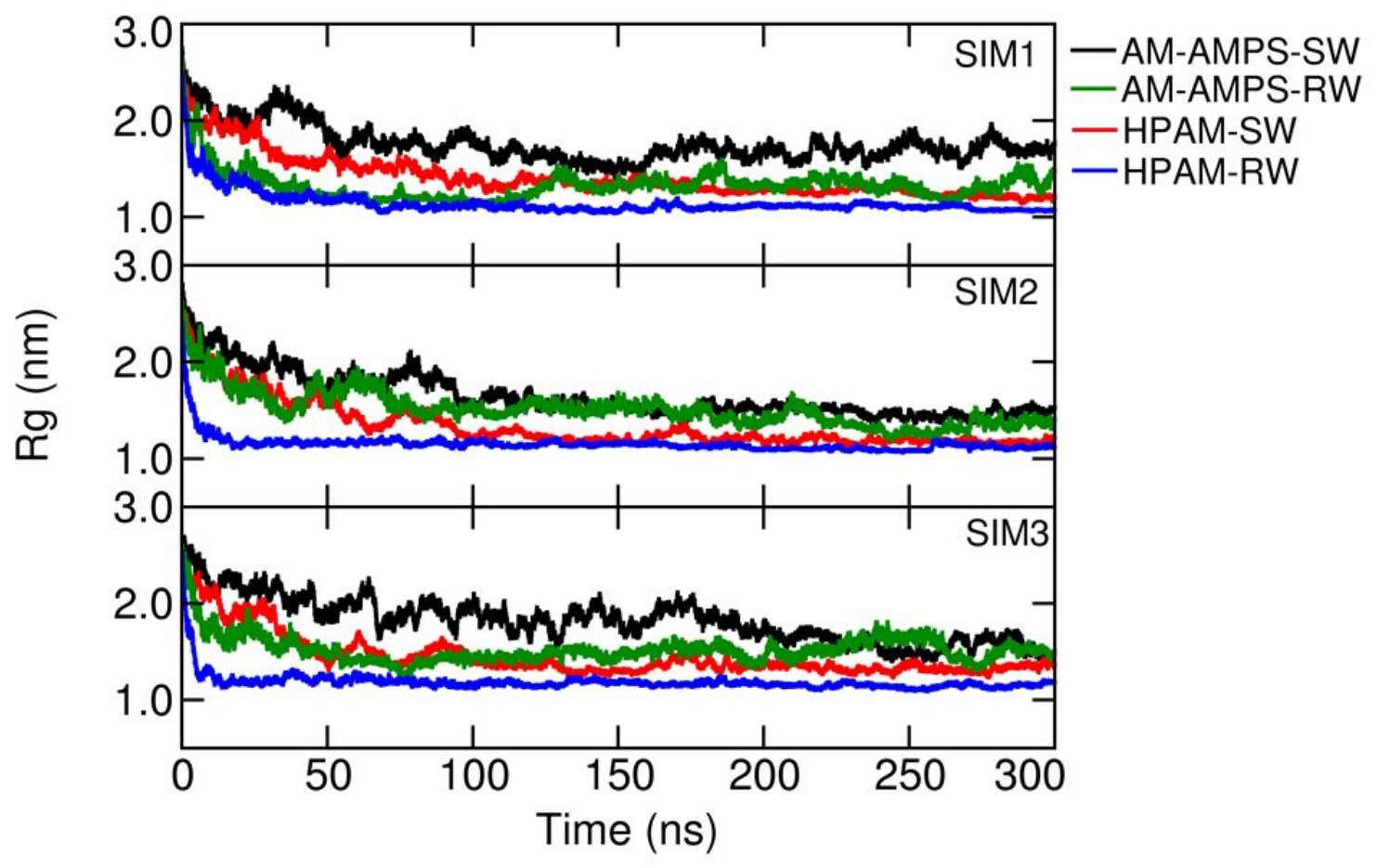


Figure S18: Radius of gyration (Rg) of AM-AMPS and HPAM polymer chains in SW, and RW conditions for the three simulations runs conducted for 300ns (multiple chain simulation).

$-S 14-$

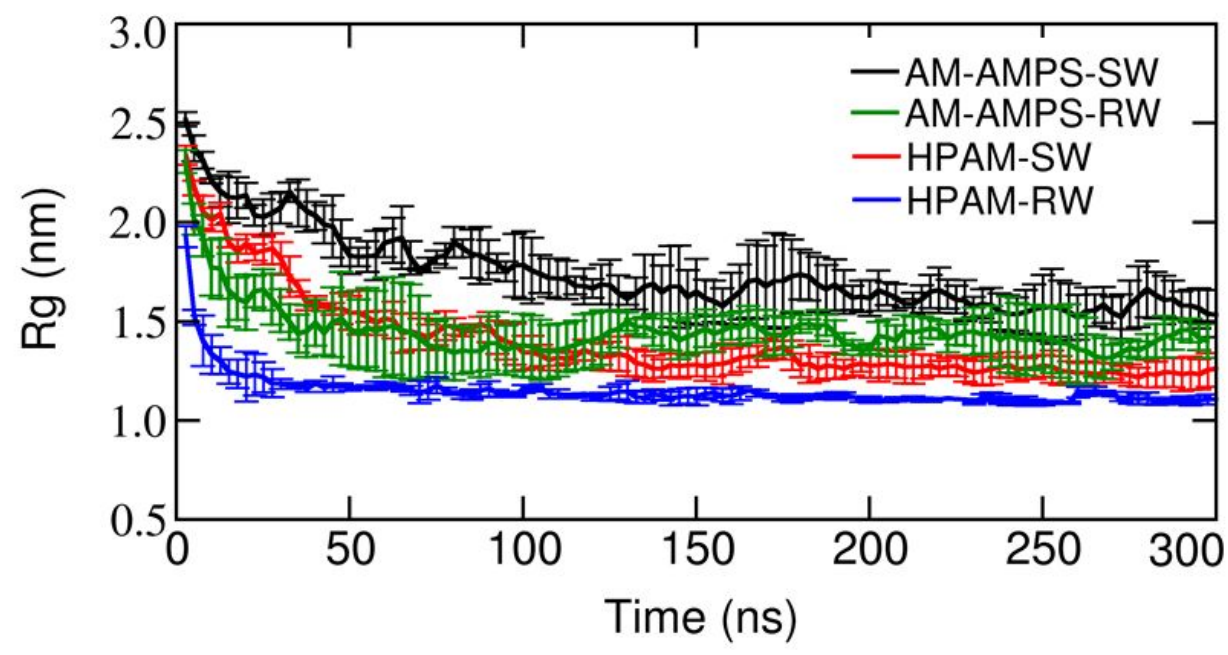

Figure S19: The average of radius of gyration of AM-AMPS, and HPAM polymer chains in SW, and RW conditions over three simulations runs of $300 \mathrm{~ns}$ and a window of $2.5 \mathrm{~ns}$. The error bars are the standard deviation over the three runs. 


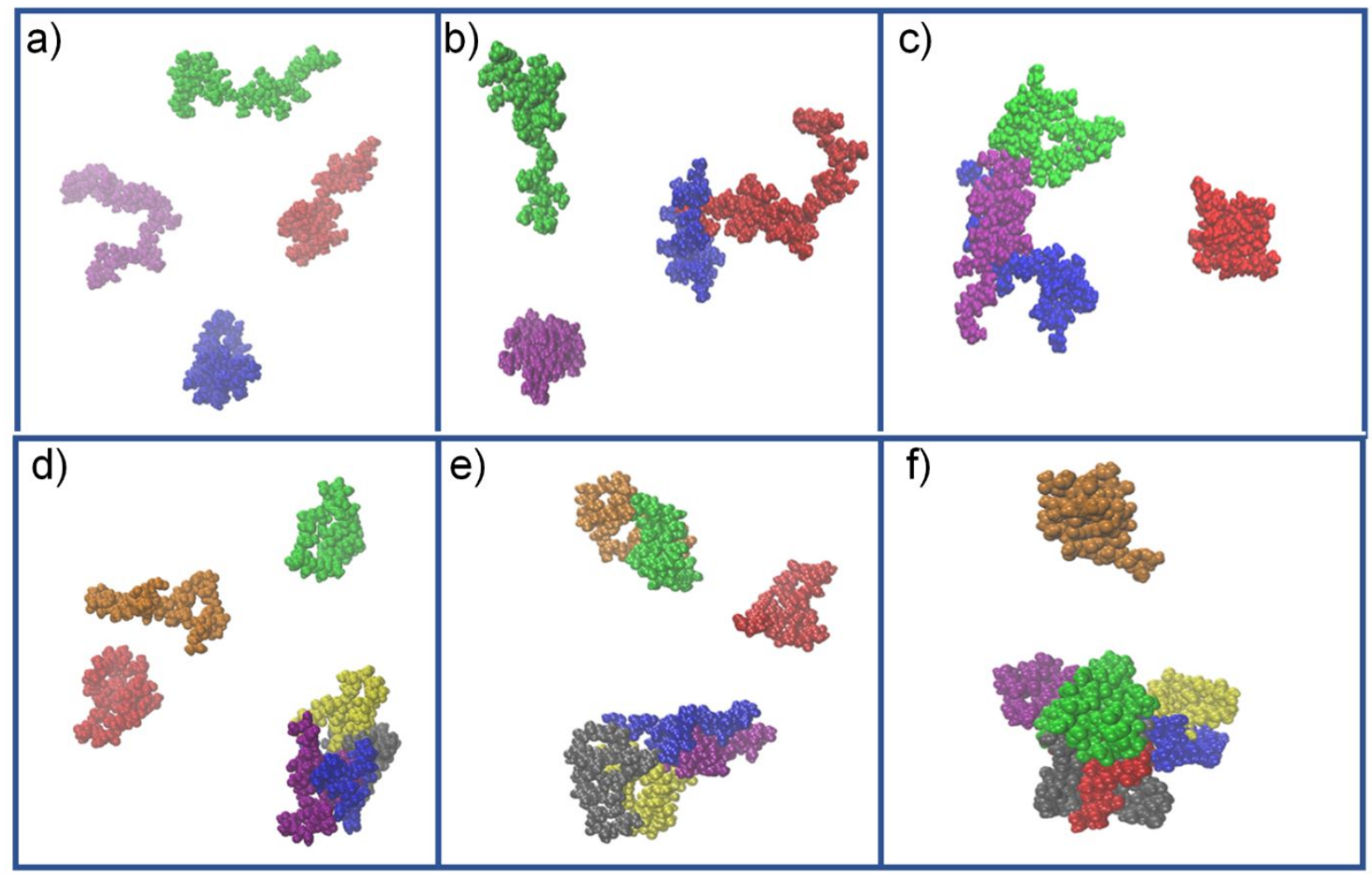

Figure S20: Snapshots of AM-AMPS (a, b, and c) and HPAM (d, e, and f) aggregates examples formed in SW and RW water. 


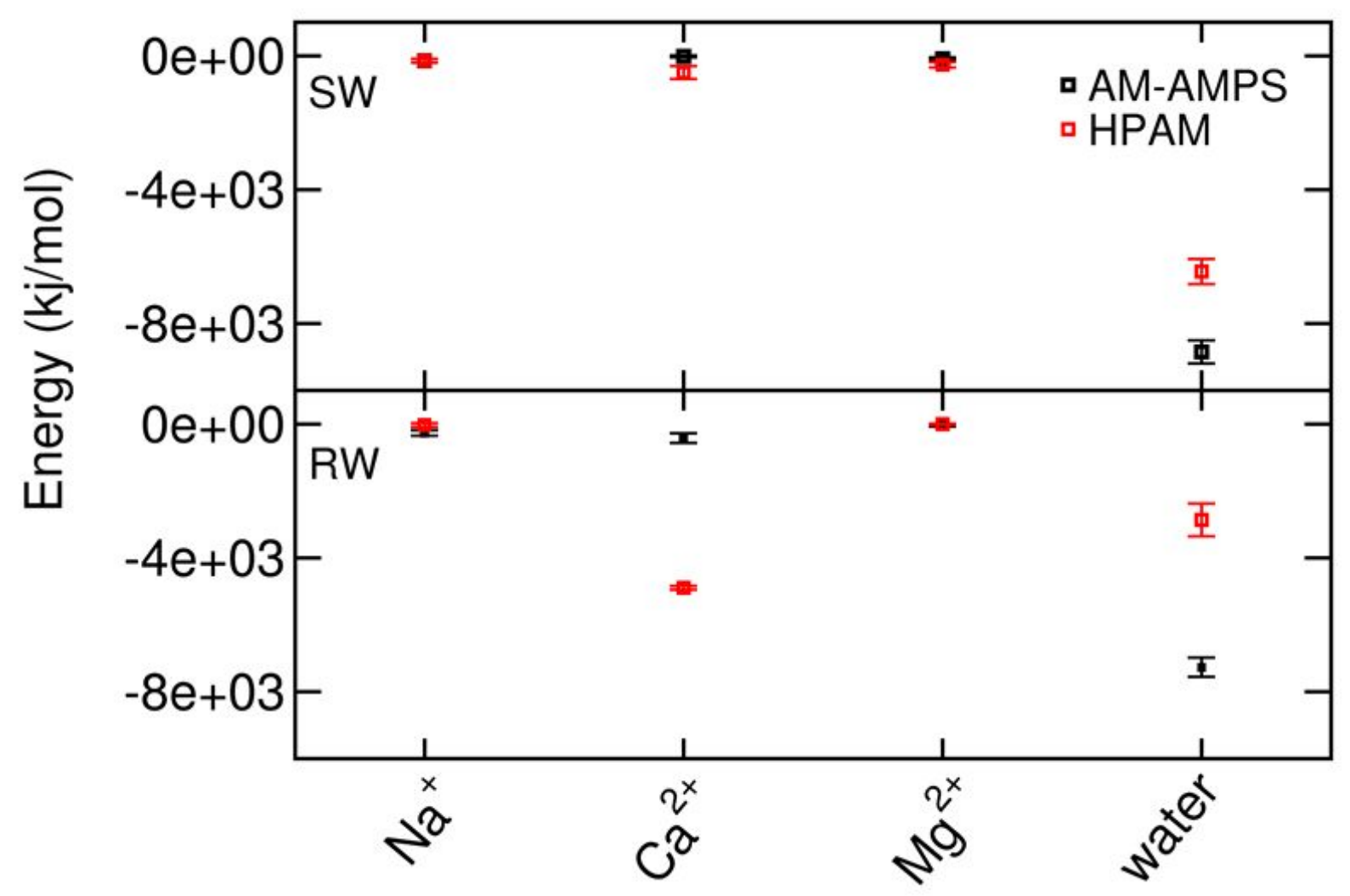

Figure S21: Molecular interactions around polymer chains simulated at $1 \mathrm{wt} \%$ concentration. Total interaction energies (electrostatic and Van Der Waals (VDW)) between polymer with ions and water molecules. The interaction energies are normalized by the number of polymer chains. The interactions are averaged over three simulation runs. 


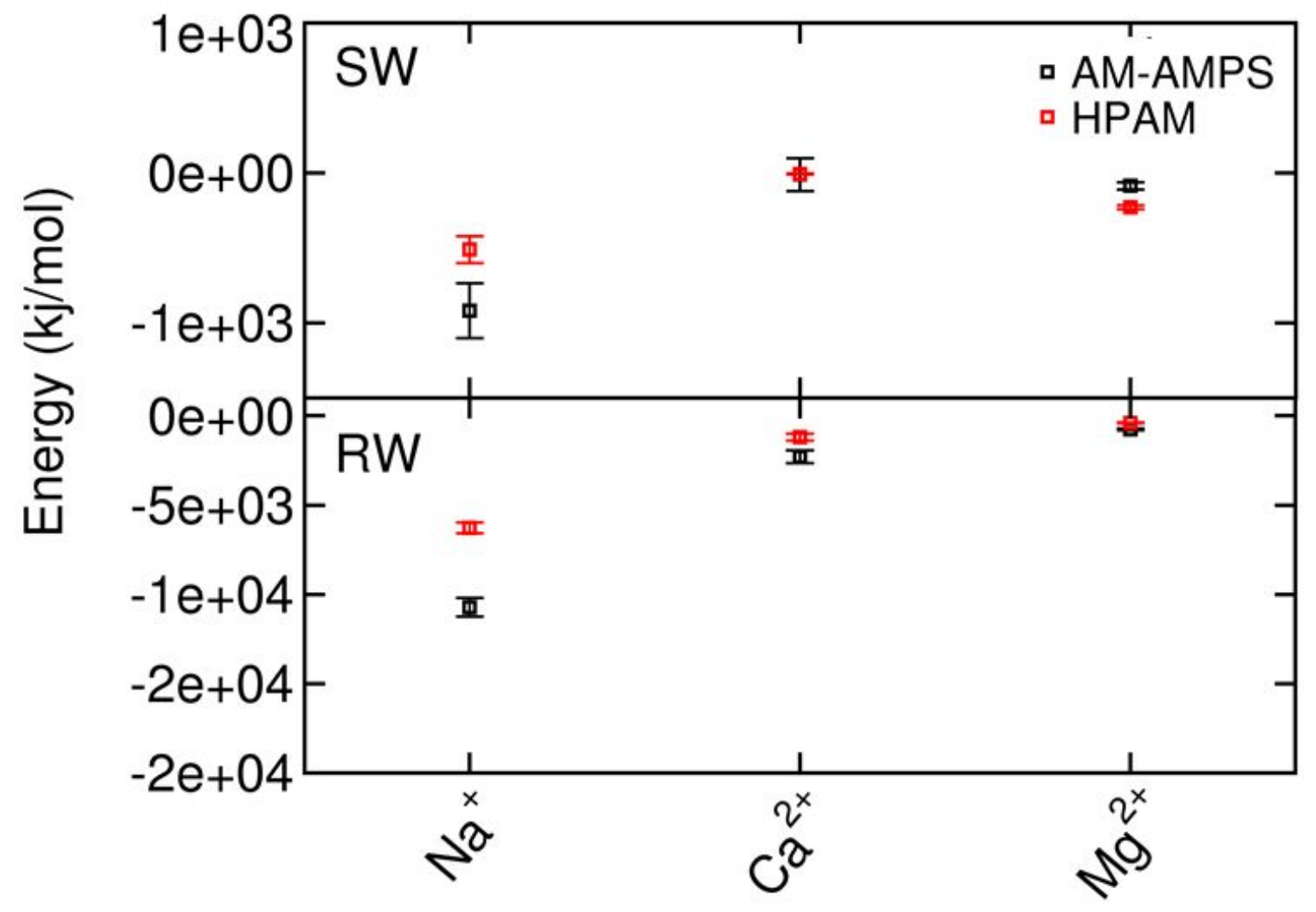

Figure S22: Total interaction energies (electrostatic and Van Der Waals (VDW)) between ions ( $\mathrm{Na}, \mathrm{Mg}, \mathrm{Ca}$ ) with $\mathrm{Cl}^{-}$anions in HPAM, and AM-AMPS polymer solutions at $1 \mathrm{wt} \%$ concentration. The interactions are averaged over three simulation runs. 


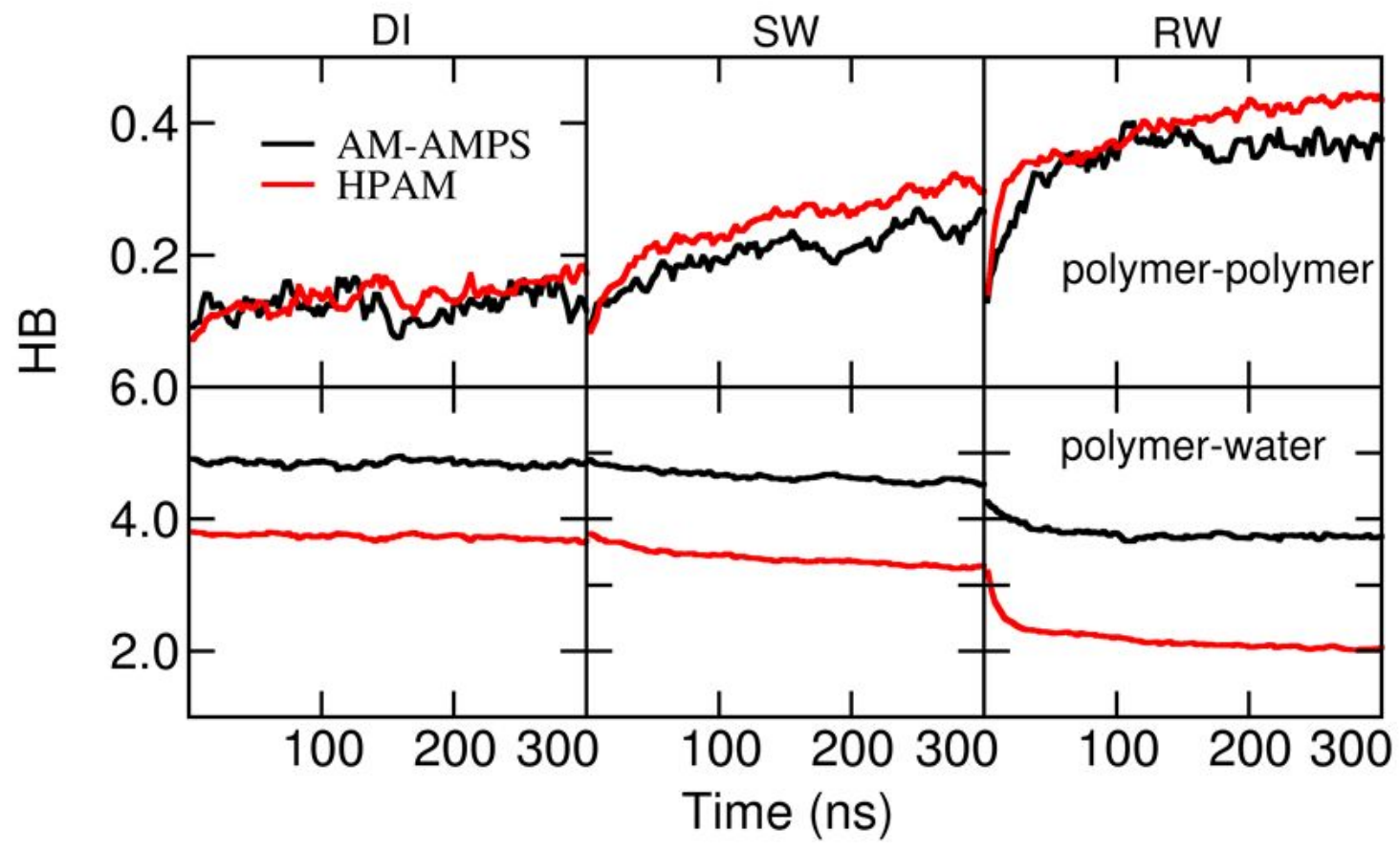

Figure S23: Hydrogen bond (HB) established between polymer-polymer (upper panel) and polymer-water (lower panel) calculated for 300ns and normalized by the degree of polymerization (i.e. in the case of HPAM, total HB divided by the total number of mers (350, 7 chains), and in the case of AM-AMPS divided by 200 mers (4 chains). The polymer concentration is $1 \mathrm{wt} \%$. SW, and RW are averaged over three simulation runs. 


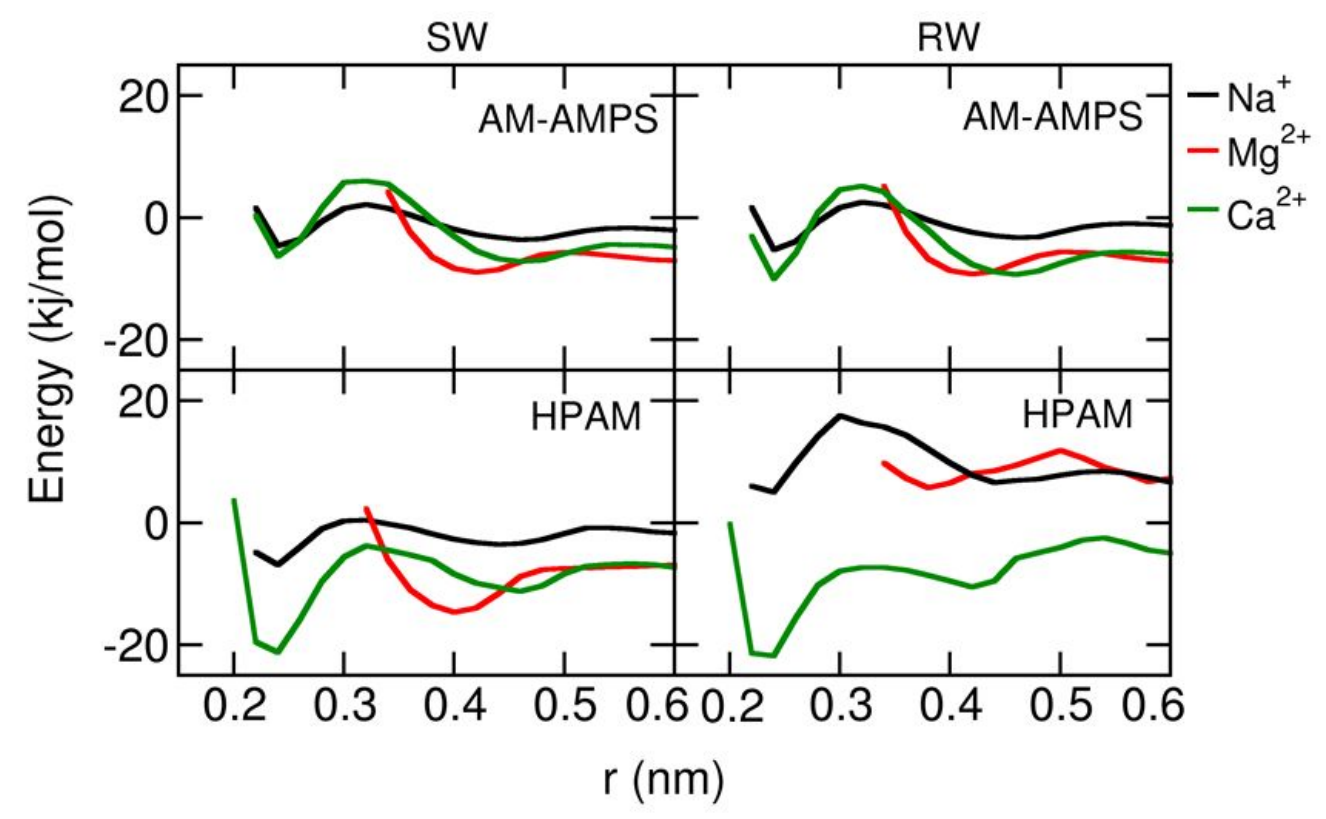

Figure S24: Potential mean force (PMF) calculated for the polymer-ion, and polymer-water interactions for AM-AMPS and HPAM used radial distribution function depicted in Figure 9. PMFs are calculated in SW and RW conditions and averaged over three simulation runs.

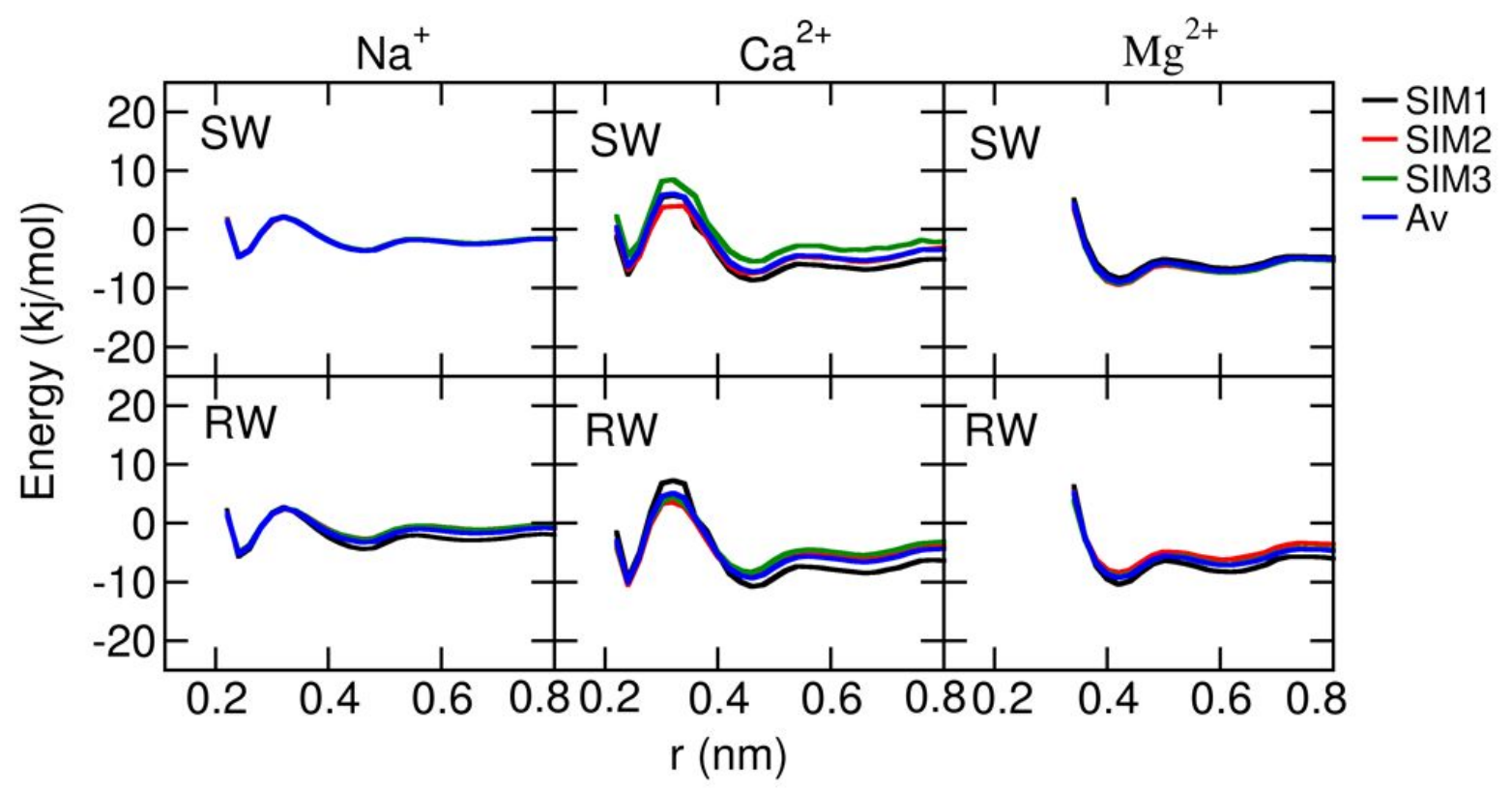


Figure S25: Potential mean force (PMF) calculated for the polymer-ion, and polymer-water interactions for AM-AMPS used radial distribution function depicted in Figure 9. PMFs are calculated in SW and RW conditions for three simulation runs.

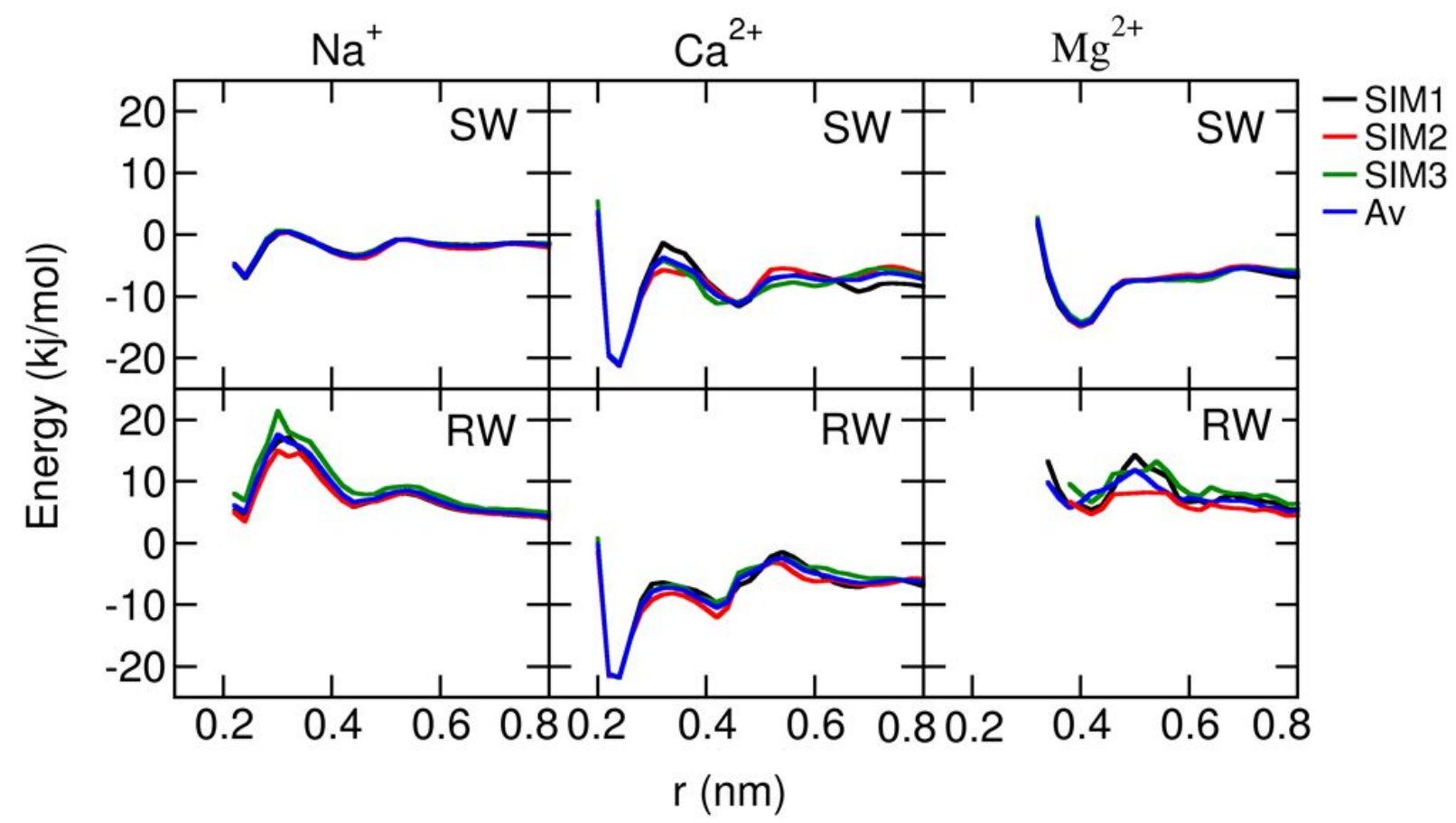

Figure S26: Potential mean force (PMF) calculated for the polymer-ion, and polymer-water interactions for HPAM used radial distribution function depicted in Figure 9. PMFs are calculated in SW and RW conditions and for three simulation runs. 
-S20- 

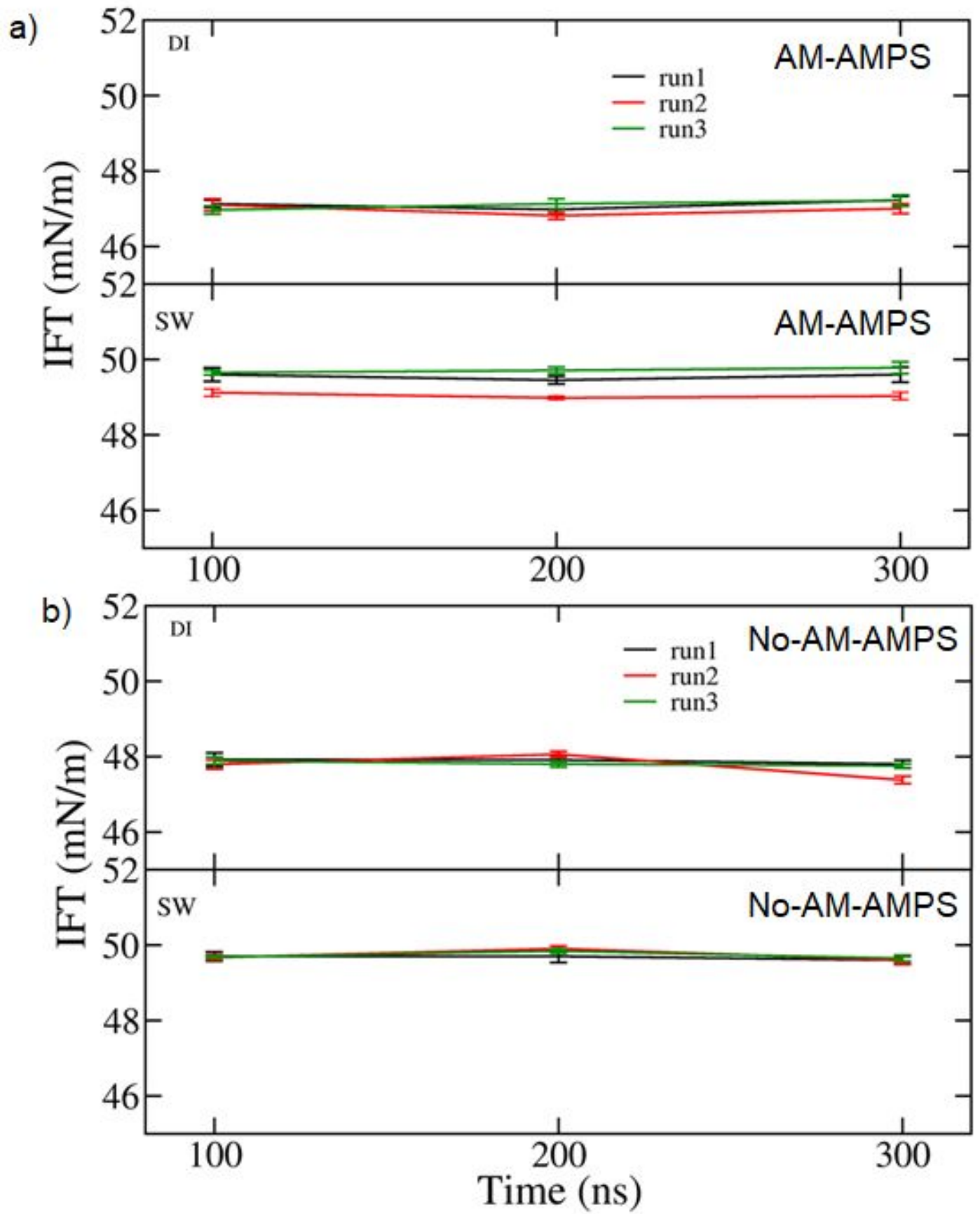

Figure S27: IFT of three simulation replicates in presence (a) and absence (b) of AM-AMPS polymer at the interface of freshwater-oil (mixture of non-polar components). 

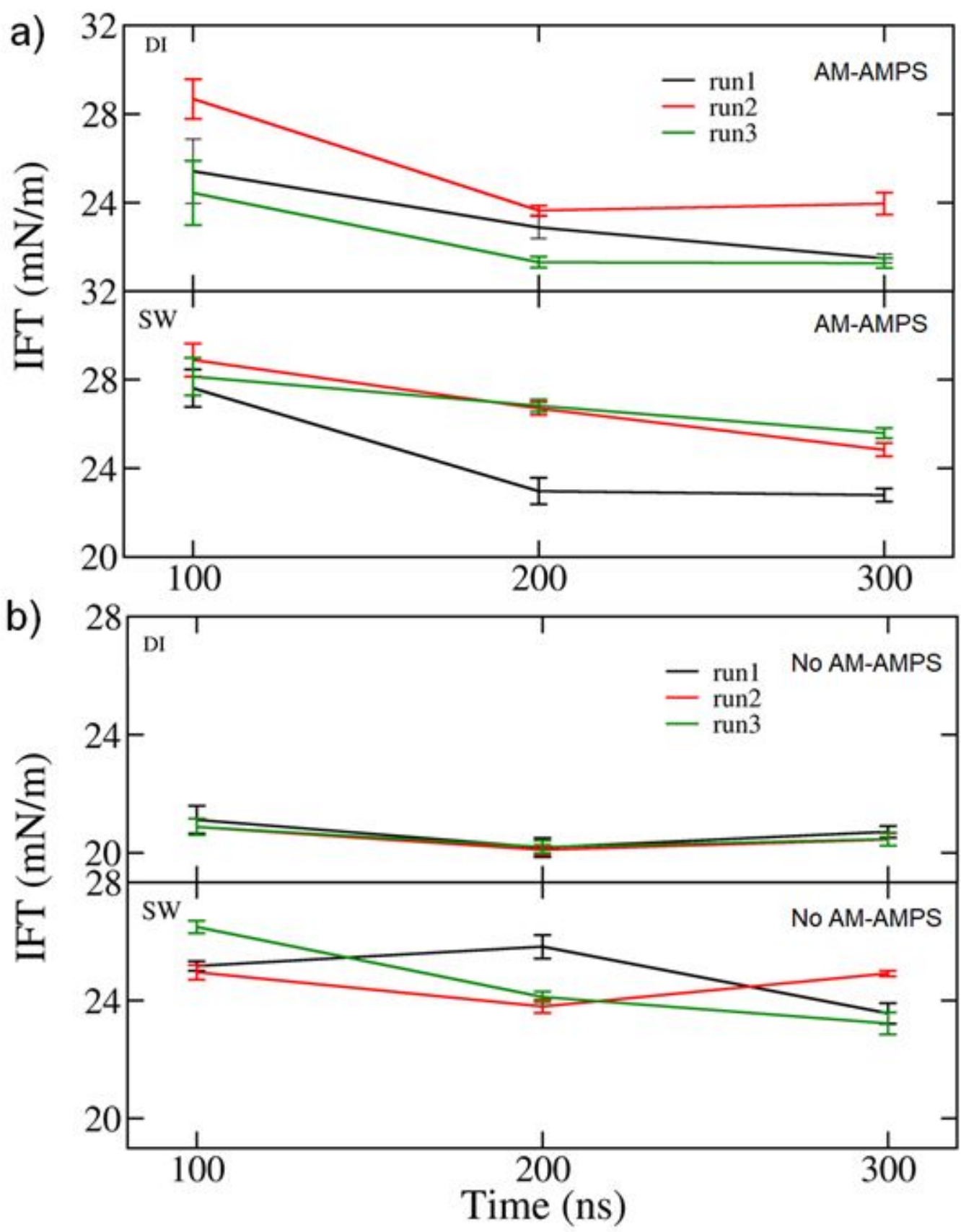

Figure S28: IFT of three simulation replicates in presence (a) and absence (b) of AM-AMPS polymer at the deionized water and seawater-oil interfaces (mixture of polar and non-polar components). Note for the average of IFT in presence of AM-AMPS in the case of Oil-B are taken for the last $200 \mathrm{~ns}$ over the three replicates. 

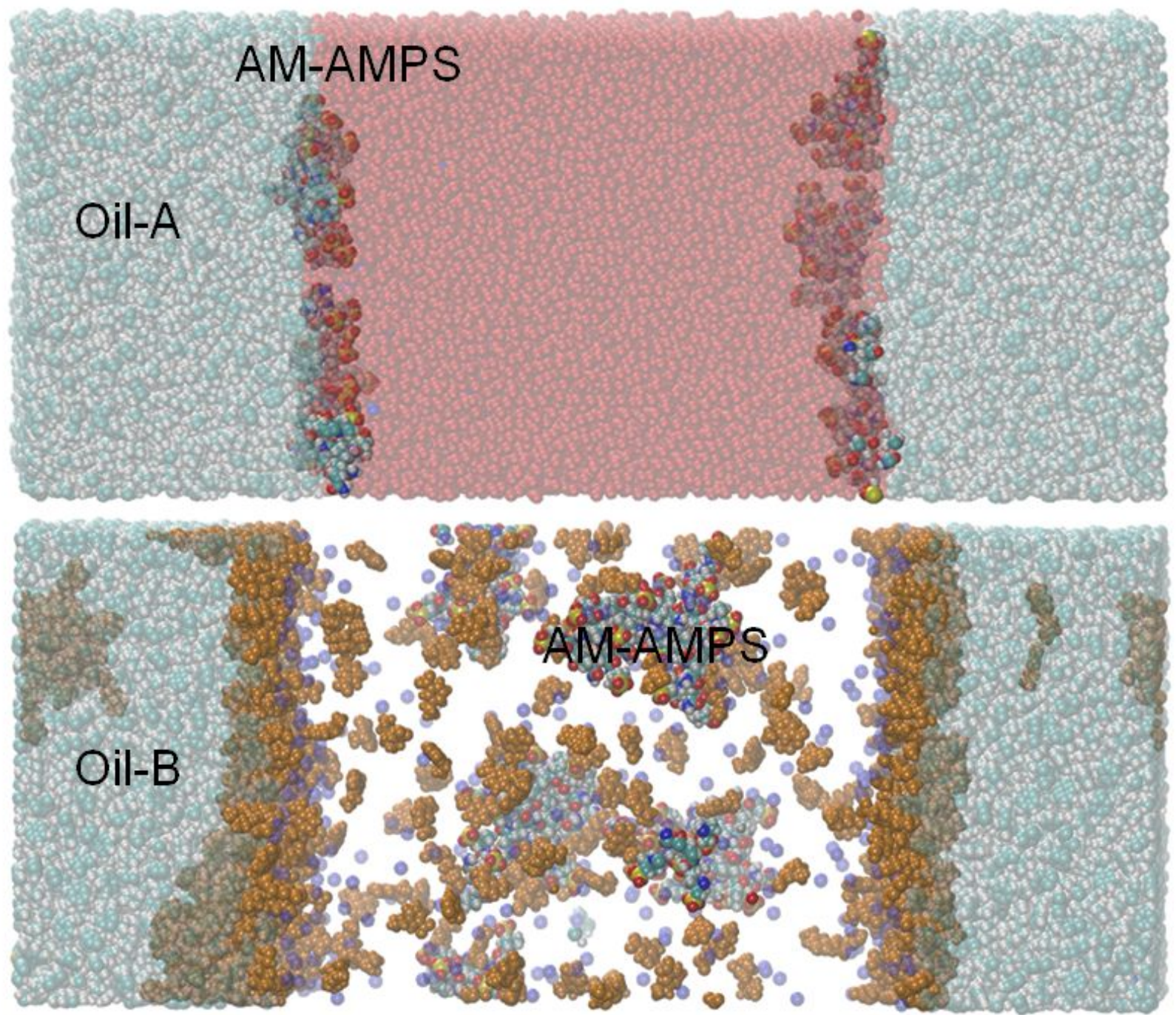

Figure S29: DI-oil interfaces (Oil-A is a mixture of non-polar components, and Oil-B: is a mixture of polar and non-polar components). Non-polar components are shown in trasparent spheres, polar components (3-cyclohecyl propionic, 3-ethylbenzoic, and nonanoic acids) are shown in orange 
spheres. Color code of Ions; $\mathrm{Na}^{+}$:blue, $\mathrm{Ca}^{2+}$ :green, $\mathrm{Mg}^{2+}$ :purple, and $\mathrm{Cl}^{-}$:yellow. The polymer is in $1 \mathrm{wt} \%$ concentration (i.e. four chains).

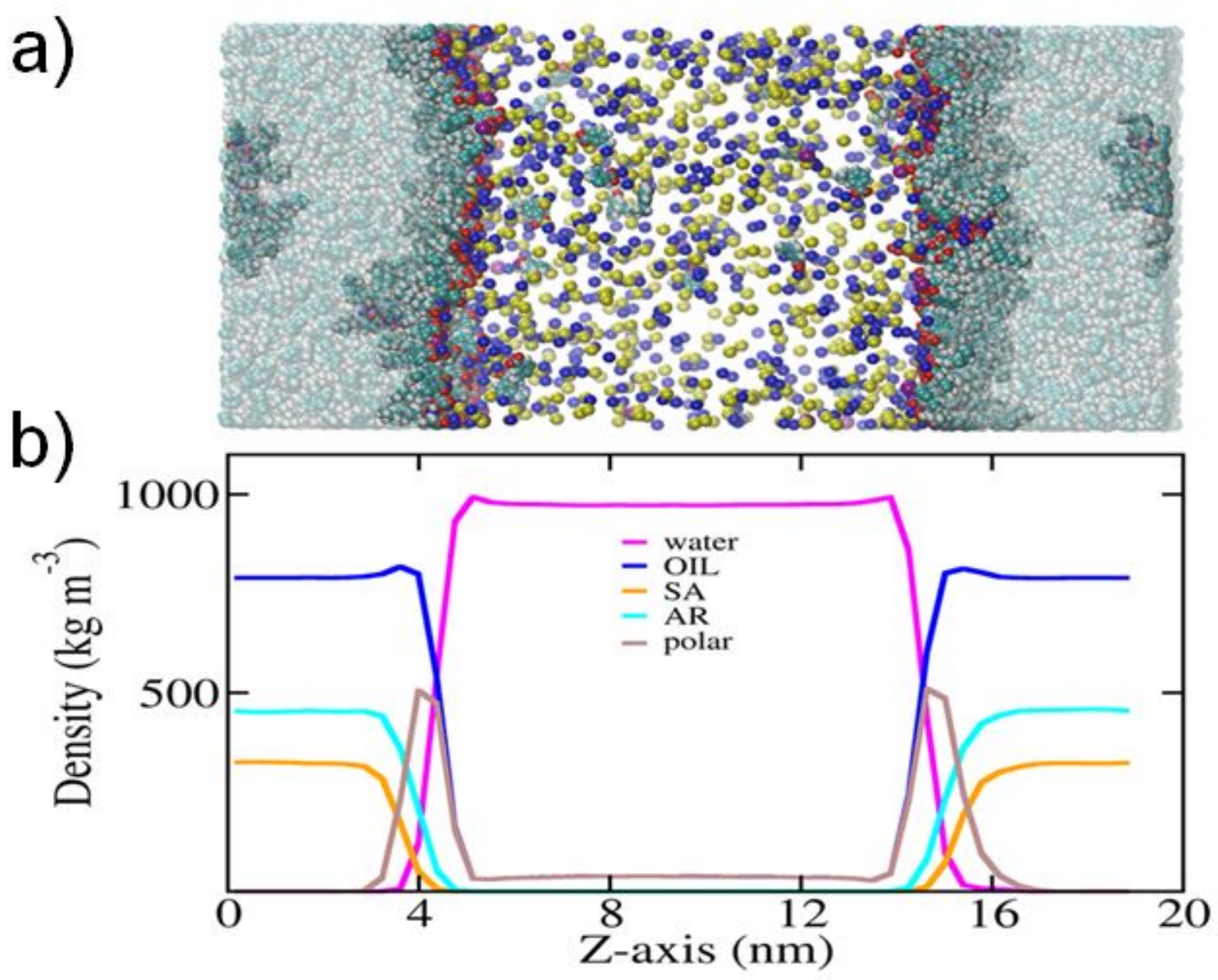


Figure S30: Seawater-oil interfaces in absence of AM-AMPS using Oil-B (a). The partial density of the different components of the aqueous and oil phases along the normal of the interface (b).

\section{References}

(1) Abdel-Azeim, S.; Sakthivel, S.; Kandiel, T. A.; Kanj, M. Y. Specificity and Synergy at the OilBrine Interface: New Insights from Experiments and Molecular Dynamics Simulations. Energy Fuels 2021, acs. energyfuels.1c02133; DOI: 10.1021/acs.energyfuels.1c02133.

; Krzysztof Murzyn, Maciej Bratek, and Marta Pasenkiewicz-Gierula, Refined OPLS A11Atom Force Field Parameters for n-Pentadecane, ; Methy1 Acetate, and Dimethy1 Phosphate ; J. Phys. Chem. B 2013, 117, 16388-16396.

; Dihedral parameters for flexible alkanes in Ryckarte-Bellemans (kj/mol)

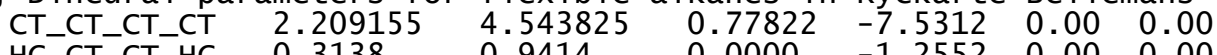

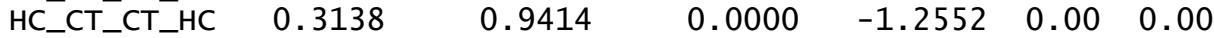

; José N. Canongia Lopes, Agílio A. H. Pádua, and Karina Shimizu,Molecular Force Field for Ionic Liquids IV:

; Trialkylimidazolium and Alkoxycarbonyl-Imidazolium Cations; Alkylsulfonate and Alkylsulfate Anions, J. Phys. Chem. B 2008, 112, 16, 5039-5046.

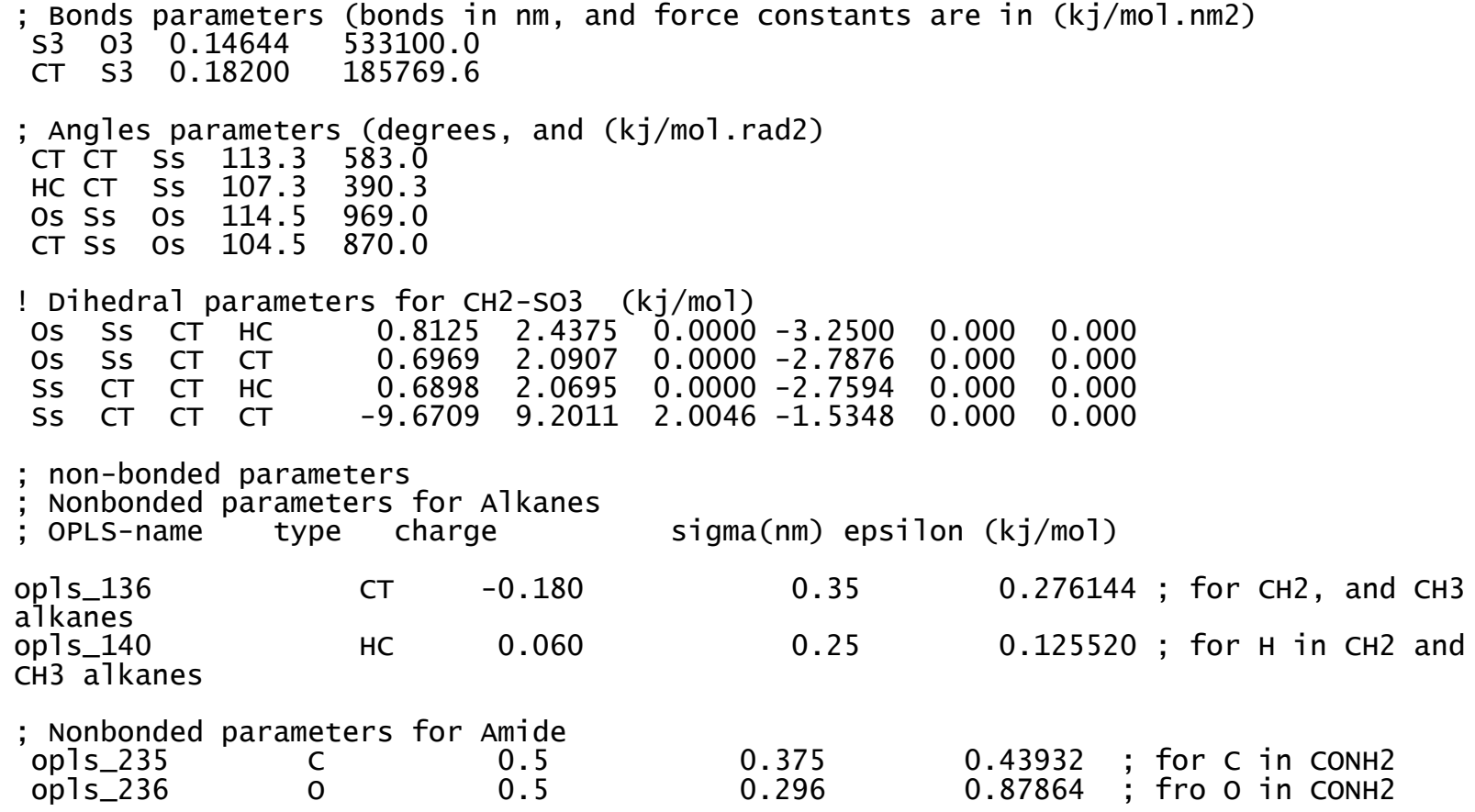




\begin{tabular}{|c|c|c|c|c|c|}
\hline $\begin{array}{l}\text { op1s_237 } \\
\text { op1s_240 }\end{array}$ & $\begin{array}{l}\mathrm{N} \\
\mathrm{H}\end{array}$ & $\begin{array}{r}-0.76 \\
0.38\end{array}$ & $\begin{array}{l}0.325 \\
0.000\end{array}$ & $\begin{array}{l}0.71128 \\
0.00000\end{array}$ & $\begin{array}{l}\text {; for } \mathrm{N} \text { in } \mathrm{CONH} 2 \\
\text {; for } \mathrm{H} \text { in } \mathrm{CONH} 2\end{array}$ \\
\hline $\begin{array}{l}\text { Nonbonded } \\
\text { opls_271 } \\
\text { op 1s_272 }\end{array}$ & $\begin{array}{c}\text { parameters } \\
\text { C } \\
\text { O }\end{array}$ & $\begin{array}{c}\text { for Acrylate } \\
0.7 \\
-0.8\end{array}$ & $\begin{array}{l}0.375 \\
0.296\end{array}$ & $\begin{array}{l}0.43932 \\
0.87864\end{array}$ & $\begin{array}{l}\text {; for } \mathrm{C} \text { in } \mathrm{COO}- \\
\text {; for } \mathrm{O} \text { in } \mathrm{COO}-\end{array}$ \\
\hline $\begin{array}{l}\text { Nonbonded } \\
\text { opls_443 } \\
\text { opls_444 } \\
\text { opls_Ss } \\
\text { opls_Os }\end{array}$ & $\begin{array}{c}\text { parameters } \\
\text { CT } \\
\text { HC } \\
\text { S } \\
\text { O }\end{array}$ & $\begin{array}{l}\text { for } \mathrm{CH}_{2}-\mathrm{SO} 3 \\
-0.079 \\
0.006 \\
1.101 \\
-0.678\end{array}$ & $\begin{array}{l}0.350 \\
0.250 \\
0.355 \\
0.315\end{array}$ & $\begin{array}{l}0.276144 \\
0.125520 \\
1.0460 \\
0.8368\end{array}$ & $\begin{array}{l}\text {; for } \mathrm{C} \text { in } \mathrm{CH} 2-\mathrm{SO} 3 \\
; \text { for } \mathrm{H} \text { in } \mathrm{CH} 2-\mathrm{SO} 3 \\
; \text { for } \mathrm{S} \text { in } \mathrm{CH} 2-\mathrm{SO} 3 \\
\text {; for } \mathrm{O} \text { in } \mathrm{CH} 2-\mathrm{SO} 3\end{array}$ \\
\hline
\end{tabular}

; Force field for ions

$\begin{array}{llllll}\text { OPLS-name } & \text { atom } & \text { mass } & \text { charge } & \text { sigma }(\mathrm{nm}) & \text { epsi1on }(\mathrm{kj} / \mathrm{mo} 1) \\ \text { opls_407 } & \mathrm{Na}+ & 22.98977 & 1.000 & 3.33045 \mathrm{e}-01 & 1.15980 \mathrm{e}-02 \\ \text { op1s_411 } & \text { Mg2+ } & 24.30500 & 2.000 & 1.64447 \mathrm{e}-01 & 3.66118 \mathrm{e}+00 \\ \text { op1s_412 } & \text { Ca2+ } & 40.08000 & 2.000 & 2.41203 \mathrm{e}-01 & 1.88136 \mathrm{e}+00 \\ \text { op1s_401 } & \text { C1- } & 35.45300 & -1.000 & 4.41724 \mathrm{e}-01 & 4.92833 \mathrm{e}-01\end{array}$

; Force field for $\left[\mathrm{SO}_{4}\right]^{2-}$

; The examples of pertechnetate (TCO4-) and sulfate (SO42-), Christopher D. Williams and Paola Carbone,

; The Journal of Chemical Physics 143, 174502 (2015); doi: 10.1063/1.4934964 ; mame 3 nrexc1

[ atoms ] ; nr type resi res atom cgnr charge mass ; simga (nm) Epslion (kj/mol)

\begin{tabular}{|c|c|c|c|c|c|c|c|}
\hline $\begin{array}{l}1 \text { op1s_966 } \\
8.37000 \mathrm{e}-01\end{array}$ & 1 & SUL & S1 & 1 & 0.800000 & 32.06000 & ; $3.55000 \mathrm{e}-01$ \\
\hline 2 op1s_967 & 1 & SUL & 01 & 2 & -0.700000 & 15.99940 & ; $3.68000 \mathrm{e}-01$ \\
\hline 6.50000e-01 3 op_967 & 1 & SUL & 02 & 3 & -0.700000 & 15.99940 & $3.68000 \mathrm{e}-01$ \\
\hline $\begin{array}{c}4 \text { op } 1 \mathrm{~s} \_967 \\
6.50000 \mathrm{e}-01\end{array}$ & 1 & SUL & 03 & 4 & -0.700000 & 15.99940 & $3.68000 \mathrm{e}-01$ \\
\hline $\begin{array}{c}5 \text { opls_967 } \\
6.50000 \mathrm{e}-01\end{array}$ & 1 & SUL & 04 & 5 & -0.700000 & 15.99940 & $3.68000 \mathrm{e}-01$ \\
\hline
\end{tabular}

[ bonds ]

$\begin{array}{crclc}\text { [ bi } & \text { aj } & \text { funct } & r & k \\ 1 & 2 & 1 & 1.50 \mathrm{e}-01 & 4.3974 \mathrm{e}+05 \\ 1 & 3 & 1 & 1.50 \mathrm{e}-01 & 4.3974 \mathrm{e}+05 \\ 1 & 4 & 1 & 1.50 \mathrm{e}-01 & 4.3974 \mathrm{e}+05 \\ 1 & 5 & 1 & 1.50 \mathrm{e}-01 & 4.3974 \mathrm{e}+05\end{array}$

$\begin{array}{crrclr}\text { [ angles ] } & & & & & \\ \text { ai } & \text { aj } & \text { ak } & \text { funct } & \text { theta } & \text { cth } \\ 2 & 1 & 3 & 1 & 1.09465 \mathrm{e}+02 & 1171.6 \\ 2 & 1 & 4 & 1 & 1.09465 \mathrm{e}+02 & 1171.6 \\ 2 & 1 & 5 & 1 & 1.09465 \mathrm{e}+02 & 1171.6 \\ 3 & 1 & 4 & 1 & 1.09465 \mathrm{e}+02 & 1171.6 \\ 3 & 1 & 5 & 1 & 1.09465 \mathrm{e}+02 & 1171.6\end{array}$




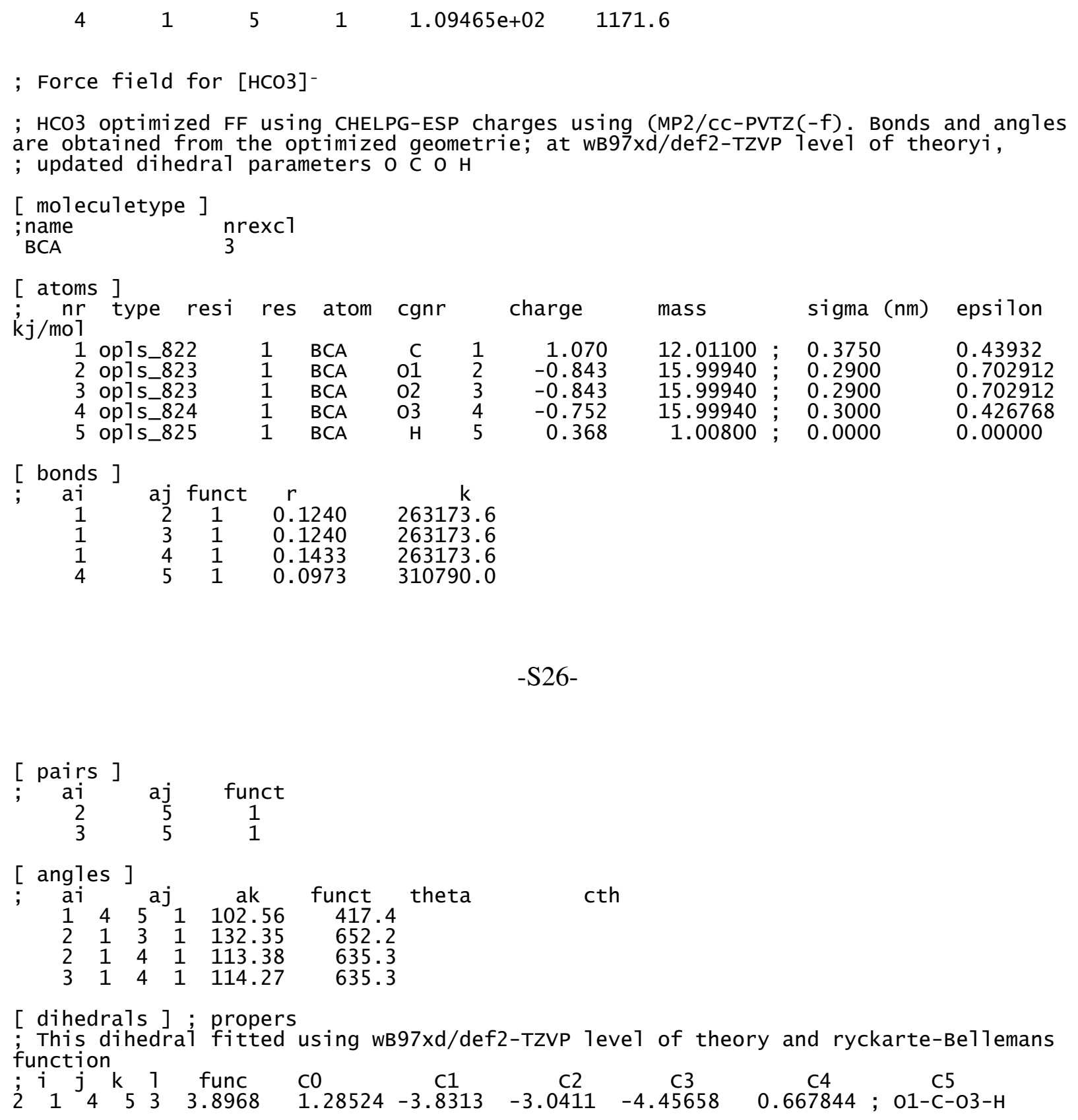


-S27- 